\title{
Searching on campus? The marriage market effects of changing student sex ratios
}

\author{
Nico Pestel ${ }^{1}$
}

Received: 6 May 2020 / Accepted: 17 April 2021 / Published online: 16 May 2021

(c) The Author(s) 2021; This article is published with open access at Springerlink.com

\begin{abstract}
This paper studies how secular changes in the student sex ratio affect marriage market outcomes for university graduates. Using data from Germany, I find that a higher owngender share within the field of study reduces marriage market opportunities for women, while the opposite is true for men. Moreover, an imbalanced student sex ratio changes the composition of couples. For women, a higher female share decreases the probability of having a spouse from the same field, while men are more likely to marry down with respect to educational status when the male share is high. These findings suggest that the secular changes in the sex ratio of university students have important implications beyond the labor market by affecting the household composition among the high-skilled population.
\end{abstract}

Keywords Marriage markets $\cdot$ Sex ratio $\cdot$ Higher education $\cdot$ Germany

JEL classification $\mathrm{D} 10 \cdot \mathrm{I} 23 \cdot \mathrm{I} 24 \cdot \mathrm{J} 12$

\section{Introduction}

How does the gender composition in university affect students' marriage market outcomes? Over the past decades, most Western societies have experienced a secular rise in the share of women attending university education (Goldin et al., 2006). ${ }^{1}$ In some fields of study, for example medicine or law, this has substantially changed the student sex ratio. While until the 1970s, men were a majority among students in

\footnotetext{
Nico Pestel

pestel@iza.org

1 Institute of Labor Economics (IZA), Schaumburg-Lippe-Str. 5-9, 53113 Bonn, Germany
}

\footnotetext{
1 Figure 11 shows that in Germany in 2003 the share of university-educated women among older cohorts was below $15 \%$ and well below the share of university-educated men, while the gender gap in higher education has almost closed for younger cohorts in 2011 with more than $25 \%$ of men and women aged 30-34 holding a university degree.
} 
these fields, they became a minority in the 2000s. Given that students frequently meet classmates of similar age and ability right before marrying age, it is possible that this shift in student sex ratios has affected the marriage market (Blossfeld and Timm, 2003). ${ }^{2}$ A higher share of women in university means that more women are competing for fewer men, which may change the search behavior of both genders. Imbalanced sex ratios typically favor the scarcer gender because of reduced partner search costs and increased bargaining power. Marriage market conditions, in turn, may affect labor force participation and working hours of women (GrossbardShechtman and Neideffer, 1997, Grossbard and Granger, 1998).

In this paper, I investigate how secular changes in the student sex ratio within fields of study affect the couple formation and marriage prospects of male and female university graduates using data from Germany. Different from the U.S., university teaching as well as students' social environment in Germany are traditionally strongly segmented by fields of study. Almost $90 \%$ of German university students do not reside on campus, making it more unlikely to closely interact with students from other fields of study. ${ }^{3}$ In addition, German universities are typically scattered across university cities instead of being concentrated at a single campus. Hence, departments of different disciplines, including teaching facilities, are usually located in different places within a city. Therefore, in this setting the field-specific gender composition of students should capture the frequency of meeting a potential spouse during education. In the empirical analysis, I use aggregate information on the student sex ratio for (West) Germany broken down by 41 detailed fields of study over the period from 1977 to 2011 . The field-by-year data is matched with data from the German Microcensus waves from 2003 to 2011. Over this period, the Microcensus contains individual information on the year of graduation as well as the exact field of study for more than 30 cohorts of university graduates. This allows me to exploit variation in the field-specific student sex ratio at the time of graduation to estimate its effect on individual marriage market outcomes such as the marital status, spouses' educational attainment and field of study as well as occupation and industry.

The main identification strategy employs field of study fixed effects capturing any unobserved field-specific and time-invariant characteristics of students enrolled in a given field. Thus, variation in the gender composition comes from within fields over time. The comparison underlying the regression analysis can be illustrated as follows. A female university student enrolled in a field with a generally high share of men (e.g., a field in Engineering) in the 1970s, when the female share of students was particularly low, encounters male students very frequently during her education. Obviously, the opposite is true for male students enrolled in Engineering fields who will have to direct marital search outside their field of study or even outside the

\footnotetext{
${ }^{2}$ In Germany, individuals holding a university degree typically marry shortly after having completed education. Average age at graduation is 28.1 for men and 27.2 for women, while average age at marriage is 30.0 and 28.8 respectively (Fig. 12). On average, individuals with lower levels of education finish much earlier (men: 22.2, women: 21.3) but the average time gap between education and marriage is much larger (men: 27.7, women: 25.9). Figure 13 shows that university graduates are also significantly more likely to meet their partner in education or at work.

3 Figure 14 shows that over the past decades the share of university students in Germany living in student dorms has been around $12 \%$ while about two thirds of students live in (shared) apartments or stay with their parents (more than $20 \%$ ).
} 
university environment in order to find a spouse. While the female student share in Engineering is still rather low in the $2000 \mathrm{~s}$, a relative increase since the 1970 s implies that for female Engineering students the frequency of meeting male students is nowadays relatively lower compared to older cohorts holding any specific characteristics of women choosing Engineering constant.

However, the identification of causal effects of the student gender composition by field of study on marriage market outcomes may still raise concerns of endogenous self-selection into fields driven by marriage market considerations. Students who are mainly interested in finding a university-educated spouse may deliberately choose fields where the own gender is relatively scarce. In that case, the resulting sex ratio would result from preferences for specific marriage market outcomes and reverse causality would be an issue. ${ }^{4}$ To address this concern, I restrict the sample to admission-restricted fields in a robustness analysis. Enrolling in such a field is costly for students due to "waiting semesters" before actual admission, making it much more likely that the motivation for choosing a restricted field is primarily driven by labor market considerations. In addition, the student sex ratio within a field may be correlated with characteristics of its graduates which are expected to affect marriage market outcomes. For example, one may be worried about omitted variable bias resulting from the fact that graduates from a field with a high male share tend to earn higher salaries relative to graduates from female-dominated fields. These concerns are addressed by the field fixed effects strategy, as long as unobserved characteristics are time-invariant, as well as by the inclusion of time-varying controls for a field's graduates' average income and occupational prestige.

The results of this paper show that the student sex ratio by field of study at graduation significantly affects marriage market outcomes for students with distinct gender differences. First, a higher share of female students reduces marriage market opportunities for women. Female graduates are more likely to remain single and are less often married when women outnumber men in their field. For men, I find the exact opposite result. Surprisingly, a higher male share in the field increases the probability of being married for male students. Second, the student sex ratio significantly affects the composition of couples. Women who graduate from a predominately female field are less likely to have a partner from the same field than having a lower educated spouse. At the same time, when men are more numerous in their field of study, male students are more likely to "marry down" with respect to educational status. These results indicate that men's partner search is more likely to be outside the peer group at university when the student male share is high while women tend to search primarily within the field or at least within the university environment more generally. This interpretation is supported by additional results showing that for female graduates the spouse's graduation year is more likely to be very close when the student female share is lower. For men, a higher field-specific share of males increases the probability of having a partner working in the same industry but reduces the probability of the spouse working in the same occupation.

\footnotetext{
${ }^{4}$ However, individuals predominantly choosing fields of study where their own gender is scarce would imply that in the longer run the gender composition by field of study should become more balanced. In Section 2, I show that this is true for some fields, but is at odds with the observation that the female share increased in virtually all fields, i.e., also in those that had already been predominantly female. In addition, a number of fields are still predominantly male.
} 
This means that the student sex ratio is of great importance for marriage market opportunities for university-educated women while the work environment after graduation appears to be of additional relevance for men performing "partner search on the job" (McKinnish, 2007).

Previous studies on the effects of imbalanced sex ratios on marriage and labor market outcomes (see, e.g., Grossbard-Shechtman and Neideffer, 1997, Grossbard and Granger, 1998) have used segmentations of marriage markets by region, ethnicity or socio-economic status, especially the level of education. ${ }^{5}$ Defining separate marriage markets for high- and low-educated individuals requires the implicit assumption that both men and women prefer spouses from the same educational class. This neglects potential heterogeneity in the preferences for same-education spouses. Indeed, in a closely related paper using occupation-specific sex ratios, Mansour and McKinnish (2018) show that disproportionate rates of withinoccupation matching of couples are rather due to lower search costs within the workplace environment than preferences for a same-occupation spouse.

This paper contributes to the literature by showing that the marriage market effects stemming from variation in the student sex ratio by detailed fields of study are gender-specific. The results indicate that marriage market opportunities of female graduates are more sensitive to the gender composition of students during education since they are more likely to search within the university environment. At the same time, men's potential partner search pool additionally expands to spouses with a lower level of education. Additionally, these results are consistent with findings from the literature on social norms regarding relative income within couple households, typically stipulating that the husband should be the main earner in the household. The finding that university-educated women are more likely to be married to a sameeducation spouse while men are more likely to "marry down" when the own gender is relatively scarce within the field is in line with these gender identity norms. ${ }^{6}$ In the context of this study, an increase in the female share of students reduces women's

\footnotetext{
5 For example, Negrusa and Oreffice (2010) find that more favorable sex ratios by U.S. metropolitan areas and educational attainment for women reduce wives' labor supply but increases that of husbands. Bitler and Schmidt (2012) exploit variation across U.S. states and over time in men drafted for the Vietnam War and find that higher rates of inducted men led to significantly lower birth rates. Similarly, Abramitzky et al. (2011) use regional variation in male scarcity in France caused by World War I and find consistent evidence that men improved their position in the marriage market as they became scarcer. Edlund (1999) studies the implications of unbalanced sex ratios due to widespread son preferences in Asian countries on marriage market outcomes across social classes. Chiappori et al. (2002) show that the sex ratio and divorce laws deemed favorable to women affect bargaining power and labor supply behavior. Angrist (2002) uses variation in immigrant flows to the U.S. as a natural experiment to study the effect of sex ratios on the children and grandchildren of immigrants and consistently finds that higher sex ratios increase female bargaining power in the marriage market. One recent exception is Bičáková and Jurajda (2016) who use European labor force survey data and document a strong tendency of matching partners within eight broadly defined fields of study.
}

${ }^{6}$ For example, Bertrand et al. (2015) show that the likelihood of deviating from the social norm of the husband earning a larger share of household income affects marriage formation, women's labor supply and earnings as well as satisfaction with marriage and the likelihood of divorce. The results are also consistent with findings based on speed-dating experiments. For instance, Fisman et al. (2006) find that men prefer women whose "intelligence does not exceed their own", which would suggest that men may have a preference for partners with a lower education than themselves. Similarly, studies of online dating, e.g., Skopek et al. (2011), find that although men are willing to contact potential partners with lower educational qualifications, highly educated women tend to be averse to lower-qualified partners. 


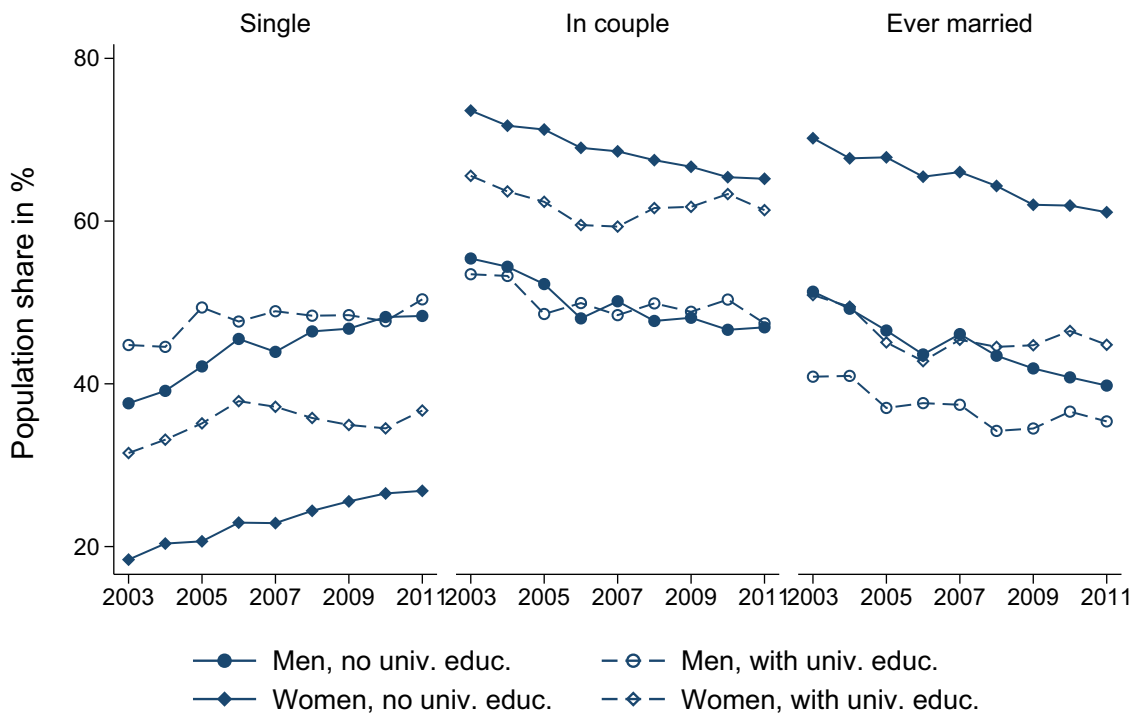

Fig. 1 Marital status by gender and university education. This graph shows the marital status among individuals aged 30-34 in Germany. Ever married includes currently married, divorced and widowed. Source: Microcensus 2003-2011, own calculations

frequency of meeting men with the same level of education. Consequently, the chances of finding a spouse with the same or even higher earnings potential are more limited, making couple formation in line with gender identity norms more difficult and, hence, less likely. ${ }^{7}$ In addition, gender compositions in educational settings more generally may have other impacts beyond direct effects on marriage market prospects, in particular students' job choices and labor market outcomes. For example, gender composition in high school or during university education may affect major choice and labor market outcomes, such as earnings growth later on (Anelli and Peri, 2017, Zölitz and Feld, 2020). Also, the gender composition between elementary and high school education affects cognitive outcomes (Lavy and Schlosser, 2011).

The remainder of the paper is organized as follows: Section 2 describes the data. The empirical strategy and the results are presented in section 3 . Section 4 concludes.

\section{Data and descriptives}

\subsection{Data sources}

The aim of this paper is to study whether secular changes in the sex ratio of students within fields of study drive observed differences in marriage market outcomes for

\footnotetext{
7 This is also relevant from a policy perspective given that assortative mating of couples has important implications for labor supply (Bredemeier and Juessen, 2013), inequality (Hyslop et al., 2001, Greenwood et al. 2014, Pestel et al., 2017, Fiorio and Verzillo, 2018) and intergenerational mobility (Ermisch et al. 2006).
} 
university graduates. The data comes from two sources. The German Microcensus (2011) is an annual cross-sectional survey of private households in Germany covering $1 \%$ of the population and contains micro data on core socio-demographic variables on the individual and household level, in particular marital status and household composition as well as detailed information on education, occupation and industry. Since wave 2003, the Microcensus provides information on the field of study and the year of graduation for individuals holding a university degree. This allows me to merge aggregate information on the student gender composition by field of study with Microcensus waves 2003-2011. This administrative data was is retrieved from various volumes of the German Statistical Yearbook (Destatis, 1992, 2012), which report the annual total and gender-specific number of students enrolled in university education by field of study. Unfortunately, the data do not allow to assign the field-specific sex ratio on a more disaggregated regional level, ideally the exact university where the degree was obtained. ${ }^{8}$

\subsection{Marriage market outcomes by university education}

Marriage market outcomes, in particular marital status of individuals as well as the composition of couple households, differ by university education. Figure 1 shows aggregate time-series of indicators of marital status over the period 2003-2011. Overall, there is a secular trend towards more singles and fewer individuals living in a (married) couple household. However, there are sizable level differences between individuals with and without university education. While for both males and females, among the group of university-educated individuals the share in single households is higher and the share in couple households is lower this difference is particularly pronounced for women: The educational gap for being single is more than ten percentage points over the period under investigation, while the gap for having ever been married is between 15 and 20 percentage points. This underlines that the marriage market behavior of university-educated individuals on average differs from individuals with a lower level of education.

Focusing on couple households, the left-hand side panel of Fig. 2 shows the share of couples where either one or both spouses hold a university degree for the full population. The share of households with one university-educated spouse has increased from about $15 \%$ in 2003 to almost $19 \%$ in 2011 . The share of dualeducated couple households increased by more than half from below $10 \%$ to $15 \%$ over the same period, among which the share of university-educated couples from the very same field of study quadrupled from $1.1 \%$ to $4.4 \%$. This means that the share of couples with at least one educated spouse increased from one fourth to about one third over the period 2003-2011. The increase in the importance of dual-educated couple households is even more pronounced when focusing on couples in the top decile of the income distribution. The share of couples where one spouse holds a university degree while the other spouse has a lower level of education has remained constant at around $30 \%$ among the richest couples. At the same time, the share of dual-educated couples increased substantially from $30 \%$ in 2003 to $45 \%$ in 2011 ,

\footnotetext{
${ }^{8}$ The German Microcensus only gives the federal state of residence at the time of the survey, which is not necessarily the federal state of university education.
} 


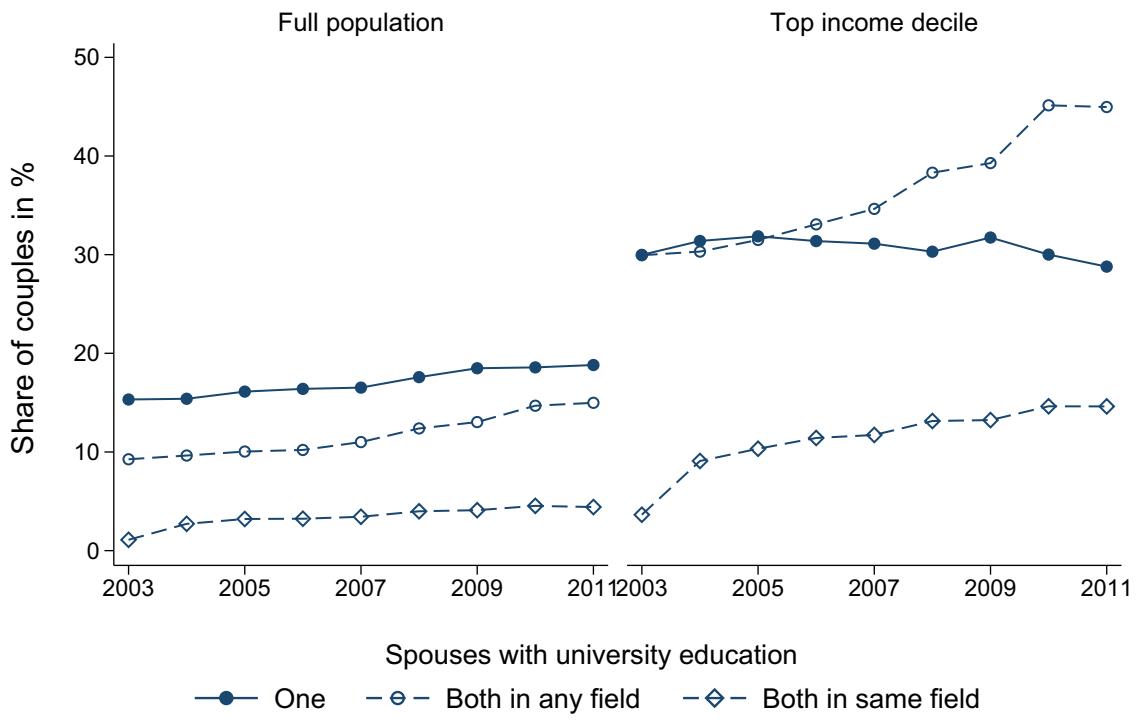

Fig. 2 Composition of couples by university education. This graph shows the share of couple households with either one or both spouses hold a university degree. The share of couples where both spouses hold a degree from the same field of study is a subgroup of the share where both spouses hold a university degree in any field of study. The sample is restricted to couple households where the household head is aged between 30 and 45. The left panel shows the composition of couples for the full population while the panel on the right-hand side is restricted to couple households within the top decile of the household income distribution. Source: Microcensus 2003-2011, own calculations

again an increase by one half. Among those, the share of same-field couples increased by more than ten percentage points from $3.6 \%$ to $14.6 \%$. Overall, almost three quarters of couple households within the top income decile comprise at least one spouse with a university degree, with a significantly growing importance of dualeducated couples. This means that couple formation among highly-educated individuals plays an increasingly important role for household composition in society, in particular at the upper end of the income distribution.

\subsection{Gender composition of students by field of study}

In the empirical analysis, I will test whether marriage market outcomes of individuals holding a university degree are affected by secular changes in the gender composition of students enrolled in the field of study at the time of university education. Figure 3 shows how the total number of university students enrolled in (West) Germany as well as the overall gender composition, indicated by the share of females, has evolved since the late-1970s. ${ }^{9}$ Over this period, the number of students in Germany more than doubled from about 850,000 to more than two million individuals enrolled in university education, while the gender composition of

\footnotetext{
${ }^{9}$ Each data year in the Statistical Yearbooks refers to the latter calender year of winter terms (typically from October to March). Harmonized data are available since 1977. East Germany is included from 1993 onwards.
} 


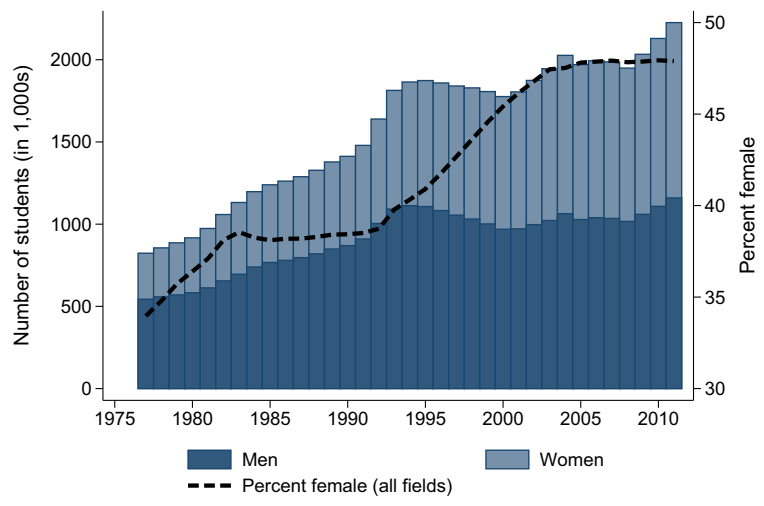

Fig. 3 University students in Germany by gender. This bar chart shows the total number of university students in Germany by gender and over time (left axis) as well as the corresponding percentage of female students (right axis). Source: Statistical Yearbooks, own calculations

students has considerably changed. In 1977, about one third of students were women and their share has been continuously increasing to $48 \%$ in $2011 .^{10}$

While an increasing share of female university students is observed for virtually all fields of study, the overall change in the gender composition is not uniformly distributed across fields. Figure 4 shows the change in the share of female students by 41 fields of study between 1977 and 2011. The substantial variation indicates that the social environment during university education in terms of the gender composition among fellow students has considerably shifted for older cohorts compared to younger cohorts of university students. A number of fields have actually switched from being predominantly male to predominantly female, for example in Architecture, Law and virtually all fields in Medical Sciences. Despite considerable increases in the share of enrolled women, fields in Engineering are still predominantly male, while fields in Humanities have become even more female. Other fields, like Economics and Business Administration or Agriculture, used to have a low female share and are nowadays rather balanced in terms of the gender composition. Only three fields have experienced very small decreases in the female share of students (Computer Sciences, Sports and Ecotrophology, a branch of nutritional science).

\subsection{Estimation sample of university graduates}

The estimation sample retrieved from the Microcensus waves 2003-2011 comprises men and women holding a university degree and have non-missing information on the year of graduation and field of study. The sample is further restricted to individuals

\footnotetext{
${ }^{10}$ The observed growth in both the total number as well as the female share of university students is due to several factors. First, the system of tertiary education in Germany expanded rapidly during the 1970s responding to the demand from large birth cohorts in the 1950s and 1960s. The state invested in additional capacities by expanding existing universities and by founding new ones. Second, the women's movement in the 1960 s promoted an increase in female participation in university education. This was, third, accompanied by the introduction of a financial support scheme targeted at students from low-income backgrounds, which turned out to be particularly beneficial for women.
} 


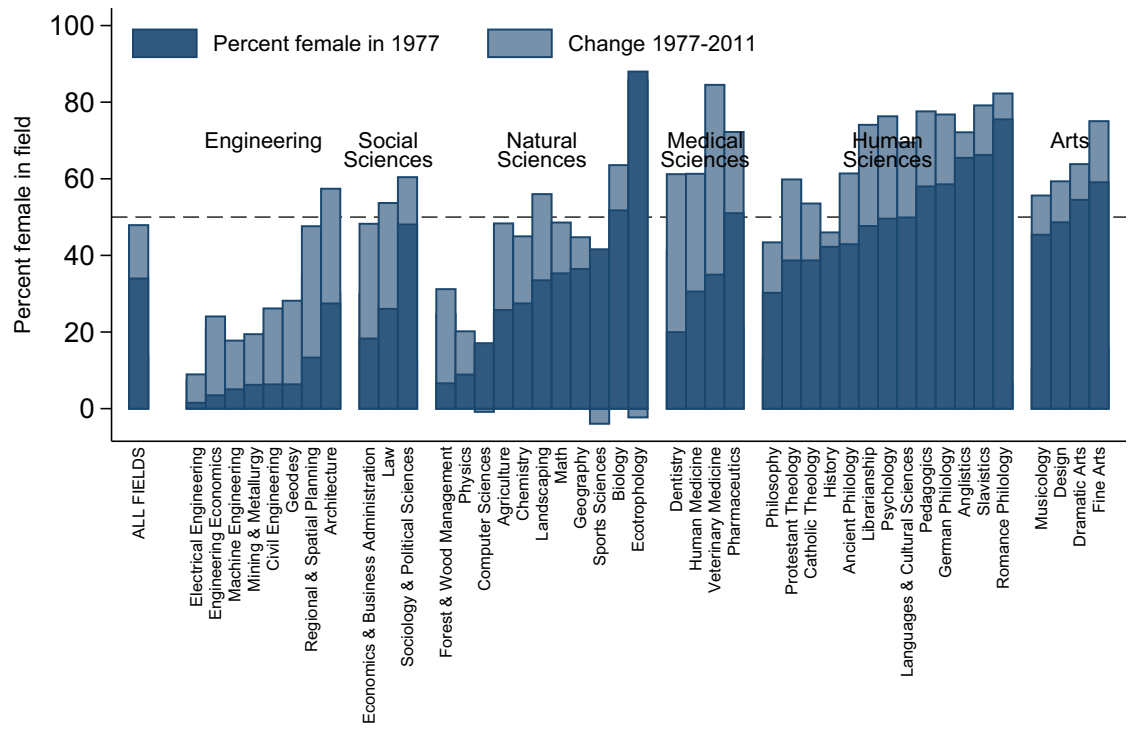

Fig. 4 Gender composition of university students by field of study. This bar chart shows the percentage of female students by field of study in 1977 (darker bars) and its change between 1977 and 2011 (lighter bars). Adding the height of the two bars gives the percentage of female students in 2011. The horizontal line indicates a female share of $50 \%$, where the gender composition is perfectly balanced. Source: Statistical Yearbooks, own calculations

aged 30-45 (birth cohorts 1958-1981). ${ }^{11}$ Individuals from East Germany are excluded since the information from the Statistical Yearbooks is limited to West Germany until 1992 and only comprises students at East German universities thereafter. In addition, individuals with a non-German nationality are dropped since the data do not allow to disentangle whether foreigners have received their degree at a university in Germany or in the country of origin. Individuals who graduated from university at age 35 or later are dropped, since their period of education may arguably not overlap as much with the age of partner search. Finally, I only use individual observations who either live in a single or couple household (both married and cohabiting), where no other household members other than the partner/spouse or dependent children are present.

Summary statistics are presented in Table 1. Overall, the full sample comprises 34,302 men and 28,165 women. The main outcome variables of interest are marital status and the characteristics of the partner with respect to university education and field of study. The share of individuals living in single households compared to couple households is very similar among the samples of men and women respectively. The share of singles is on average $28 \%$ and the share living in couple households is $67-70 \%$. More than $60 \%$ of individuals have ever been married. Most of them are currently

\footnotetext{
${ }^{11}$ As the timing of graduation as well as marriage among German university graduates is concentrated at ages just below 30 years (see Fig. 12), the lower-bound age restricts the sample to individuals who have mainly completed both education and marital search. Given that the Microcensus does not provide information on marital history and only comprises data on current marital status, the upper-bound age is chosen to restrict the sample to individuals who are most likely in their first marriage. Moreover, I exclude a very small number of same-sex couples.
} 
Table 1 Summary statistics

\begin{tabular}{|c|c|c|c|c|}
\hline \multirow{2}{*}{$\begin{array}{l}\text { Sample } \\
\text { Subsample }\end{array}$} & \multicolumn{2}{|l|}{ Men } & \multicolumn{2}{|l|}{ Women } \\
\hline & Full sample & Couple sample & Full sample & Couple sample \\
\hline \multicolumn{5}{|l|}{ Student gender composition } \\
\hline Percent own gender in field & $68.7(20.5)$ & $69.8(20.3)$ & $51.6(18.6)$ & $51.5(18.9)$ \\
\hline \multicolumn{5}{|l|}{ Marital status } \\
\hline Single $(0 / 1)$ & $0.28(0.45)$ & $0(0)$ & $0.28(0.45)$ & $0(0)$ \\
\hline In couple $(0 / 1)$ & $0.7(0.46)$ & $1(0)$ & $0.67(0.47)$ & $1(0)$ \\
\hline Ever married $(0 / 1)$ & $0.64(0.48)$ & $0.87(0.33)$ & $0.61(0.49)$ & $0.83(0.37)$ \\
\hline Currently married $(0 / 1)$ & $0.61(0.49)$ & $0.87(0.33)$ & $0.56(0.5)$ & $0.83(0.37)$ \\
\hline Divorced (0/1) & $0.03(0.16)$ & $0(0)$ & $0.04(0.2)$ & $0(0)$ \\
\hline Widowed (0/1) & $0.001(0.038)$ & $0(0)$ & $0.003(0.059)$ & $0(0)$ \\
\hline \multicolumn{5}{|l|}{ Couple composition } \\
\hline Partner no univ. degree $(0 / 1)$ & $0.37(0.48)$ & $0.53(0.5)$ & $0.21(0.41)$ & $0.31(0.46)$ \\
\hline Partner with univ. degree $(0 / 1)$ & $0.33(0.47)$ & $0.47(0.5)$ & $0.47(0.5)$ & $0.69(0.46)$ \\
\hline Partner in same field $(0 / 1)$ & $0.11(0.32)$ & $0.16(0.37)$ & $0.16(0.37)$ & $0.24(0.43)$ \\
\hline Partner in other field $(0 / 1)$ & $0.22(0.41)$ & $0.31(0.46)$ & $0.3(0.46)$ & $0.45(0.5)$ \\
\hline Partner similar year of graduation $(0 / 1)$ & $0.23(0.42)$ & $0.44(0.5)$ & $0.26(0.44)$ & $0.44(0.5)$ \\
\hline Partner in same industry $(0 / 1)$ & $0.13(0.34)$ & $0.19(0.39)$ & $0.15(0.35)$ & $0.22(0.41)$ \\
\hline Partner in same occupation $(0 / 1)$ & $0.1(0.3)$ & $0.15(0.36)$ & $0.14(0.35)$ & $0.21(0.41)$ \\
\hline \multicolumn{5}{|l|}{ Age at graduation/marriage } \\
\hline Age at graduation (years) & $26.5(2)$ & $26.4(2)$ & $25.9(2.1)$ & $25.8(2.1)$ \\
\hline Age at marriage (years) & - & $29.8(4.2)$ & - & $28.7(4.1)$ \\
\hline \multicolumn{5}{|l|}{ Field of study controls } \\
\hline Log number of students in field & $11.3(1)$ & $11.3(1)$ & $11.2(0.9)$ & $11.2(0.9)$ \\
\hline $\begin{array}{l}\text { Full-time net income in field } \\
\text { (2010 euros) }\end{array}$ & $3225(514)$ & $3241(503)$ & $2930(612)$ & $2934(608)$ \\
\hline $\begin{array}{l}\text { Occupational prestige of field } \\
\text { (ISEI score) }\end{array}$ & $65.6(6.2)$ & $65.7(6.2)$ & $65(7.1)$ & $65.1(7)$ \\
\hline \multicolumn{5}{|l|}{ Individual controls } \\
\hline Age (years) & $38.3(4.4)$ & $39(4)$ & $36.8(4.4)$ & $36.8(4.2)$ \\
\hline Living in urban area $(0 / 1)$ & $0.24(0.43)$ & $0.19(0.39)$ & $0.29(0.45)$ & $0.23(0.42)$ \\
\hline Observations & 34302 & 23947 & 28165 & 18990 \\
\hline
\end{tabular}

This table shows summary statistics (standard deviations in brackets) for a sample of university-educated individuals aged 30-45 in Germany. The percentage of the own gender in the field of study refers to the year of an individual's graduation. The binary indicator for ever married comprises currently married individuals as well as widows/widowers and divorced individuals. The binary variable for having a partner with a similar year of graduation indicates whether an individual's partner has graduated from university education in the very same year or at most one year before or after among couples where both spouses hold a university degree. The binary variables for having a partner in the same industry and the same occupation indicate that the individual's spouse is currently employed in the same 2-digit category for the Statistical Office's classification of industries (Wirtschaftszweigklassifikation, WZ2003/2008) or classification of occupation (Klassifikation der Berufe, KldB92). Full-time net income of the field is the mean net income of graduates from the same field surveyed in the same year. Occupational prestige is the mean ISEI prestige score among graduates from the same field interviewed in the same year. Urban area indicates whether the individual lives in a city with more than 500,000 inhabitants. Source: Statistical Yearbooks \& Microcensus 2003-2011, own calculations 
married at the time of the survey interview (83-87\% among the subsample of individuals living in couple households), while about $4 \%$ are either divorced or widowed.

While marital status outcomes are very similar between the samples of men and women there are substantial differences regarding the partner's characteristics among those who live in a couple household. The partners of male university graduates is in most cases a wife without a university degree (53\%) while about $47 \%$ live with a partner who has obtained the same level of education. At the same time, female graduates are much more likely to live with a university-educated man (69\%) while only $31 \%$ live with a lower-educated partner. Among those individuals living with a university-educated partner the fraction of partners having graduated in the very same field of study is about one third ( $16 \%$ for men and $24 \%$ for women).

The distinct gender patterns of selection into fields of study as shown on the aggregate level in Fig. 4 are reflected in the sample of university graduates from the Microcensus data shown in Appendix Table 6. Overall, there are 41 fields under consideration in the empirical analysis. About one third of both male and female university graduates have graduated in a field within Social Sciences (32\% and 36\% respectively). At the same time, men are substantially more likely to have a degree in an Engineering field $(37 \%)$ or Natural Sciences $(15 \%)$ than women (both $10 \%$ ). About $33 \%$ of women have graduated in a field within Human Sciences with the number for men standing at $9 \%$. Moreover, women are somewhat more likely to graduate in a medical field than men ( $8 \%$ vs. $5 \%$ ). Only $2 \%$ of men and $4 \%$ of women graduate from Arts.

The observed differences in the choice of field of study are related to the percentage of the own gender among fellow students at the time of university education. Given that the German Microcensus contains individual information on the field and year of graduation, I am able to match the aggregate information on the male and female percentages of students from the Statistical Yearbooks with the micro data. On average, men experience a $69 \%$ male share among students within the field of study while women experience a female share of $52 \%$. This variation in the gender composition across fields and within fields over time will be exploited in the regression analysis. ${ }^{12}$

\section{Estimation of marriage market effects}

\subsection{Empirical strategy}

The empirical strategy exploits variation in the gender composition of university students over time and within field of study to estimate its impact on marriage market outcomes of university graduates. The empirical model reads:

$$
y_{i f f}=\alpha+\beta \times \text { percent own gender }{ }_{f g}+X_{i t}^{\prime} \gamma+W_{f g}^{\prime} \delta+Z_{f t}^{\prime} \theta+\mu_{f}+\mu_{g}+\varepsilon_{i f f},
$$

where $y_{\text {itcfg }}$ denotes a marriage market outcome of an individual $i$ who was surveyed in year $t$ and graduated in field of study $f$ in year $g$. The outcomes are binary indicators of the marital status (single, in couple and ever married) or the composition of the couple regarding the spouse's level of education and field of study

${ }^{12}$ Figure 15 shows the distribution of the field-specific female share of students by six field groups for both men and women separately. 
(partner without university degree, partner with degree in same field, partner with degree in other field) as described in the previous section. The main variable of interest is percent own gender $_{f g}$, i.e., the percentage of students of the own gender enrolled in field of study $f$ in graduation year $g$ indicating the gender composition experienced by individual $i$ during university education. ${ }^{13}$

A simple cross-sectional OLS estimate of the coefficient $\beta$ would be biased if the selection into fields of study are explicitly driven by marriage market considerations. For example, individuals may choose a particular field of study exactly because of a favorable sex ratio in the field because the primary goal is to find a spouse during education. Another threat to the identification would be unobserved characteristics of university students enrolling in particular fields (e.g., personality traits, cognitive differences, differences in tastes and preferences, etc.) that may affect both the resulting gender composition of students by field as well as average marriage market outcomes of graduates from those fields. In order to rule out these threats to the identification, I employ a field fixed effects strategy. In Eq. (1) field fixed effects $\mu_{f}$ control for any unobserved time-invariant field of study characteristics that are related to the selection of individuals into fields of study and also take into account that some fields have been traditionally male- or female-dominated (e.g., fields in Engineering vs. fields in Humanities). Hence, I only exploit variation in the gender composition within fields over time, which rules out any endogeneity bias as long as unobserved factors characterizing selection into fields are constant over time.

There may, however, still be time-varying characteristics of a field of study that may arguably be correlated with both the sex ratio of students and marriage market outcomes of graduates and would imply omitted variable bias. For example, the gender composition of students may be correlated with graduates' expected future salaries and occupational prestige which may affect marriage market outcomes. Therefore, the vector $Z_{f t}$ controls for time-varying average full-time net income and average occupational prestige scores of graduates of field $f$ surveyed in year $t$. Finally, graduation year fixed effects $\mu_{g}$ control for any impact common to cohorts graduating at the same time that may influence marriage market outcomes, most importantly the gender composition of students across all fields of study as well as changing social norms (e.g., gender roles) over time. ${ }^{14}$ The set of individual controls $X_{i t}$ includes age, age squared, a binary indicator for living in an urban area at the time of the survey and state fixed effects, while $W_{f g}$ controls for the log total number of students enrolled in field $f$ in graduation year $g$. Eq. (1) is estimated separately for men and women using a linear probability model with standard errors $\varepsilon_{i f f}$ clustered on the field level.

\subsection{Main results: effects of student sex ratios}

\subsubsection{Effects on marital status}

The analysis of marriage market effects of the gender composition among university students begins by examining the impact of the own-gender share on outcomes

\footnotetext{
13 In a robustness check, I assign the percentage of the own gender in up to 10 years prior the year of graduation.

14 Estimation results are robust to the additional inclusion of birth cohort fixed effects as year of birth and year of graduation are highly correlated in the estimation sample $(\rho=0.93)$.
} 
related to marital status, i.e., whether a university-educated individual is single, in a couple or has ever been married at the time of the survey interview. Overall, the results for marital status outcomes imply that for university-educated women a relative scarcity of male students within the field of study hampers couple formation, in particular regarding entering marriage. At the same time, a high male share does not impair men's marriage market prospects.

The estimation results are displayed in Table 2. Panel A shows the results for the full sample of university-educated men. Overall, I find that a higher own-gender (i.e., male) share of students significantly improves marriage market prospects of men. Having experienced a higher male share among fellow students during university education reduces the probability of being single (columns (1)-(3)) and increases the probability of being in a couple relationship and of having been ever married (columns (4)-(9)). The results indicate that a one percentage point higher share of male students reduces the probability of being single by about 0.4 percentage points when including the full set of controls and fixed effects, corresponding to a $1.4 \%$ decrease at the mean value. At the same time, the probability of being in a couple is increased by 0.4 percentage points $(0.1 \%$ at the mean $)$, the effect on having been ever married is about 0.7 percentage point (about $1 \%$ at the mean). At first sight this pattern may be surprising since a relatively high own-gender share within the social environment is expected to be associated with higher competition as well as higher search costs on the marriage market. Note, however, that the marital status outcomes are not specific to the level or even field of the partner's education. The result that a higher male share within the educational peer group improves educated men's marriage market prospects implies that their partner search expands more broadly to the overall marriage market beyond the university environment. Nevertheless, the result of better marriage prospects for men from fields with a high male share is puzzling and could imply that high-educated men are attractive for women with a lower level of education.

The results for the full sample of university-educated women are presented in Panel B of Table 2 and show the exact opposite pattern. Women who experienced a higher share of female peers within their field of study are significantly more likely to remain single, while the prospects of being ever married is significantly reduced. For women, a one percentage point increase in the own-gender share increases the probability of remaining single by 0.5 percentage points $(1.8 \%$ at the mean) and reduces the probability of having been married by 0.7 percentage points $(1.1 \%$ at the mean). The results for women are in line with the expectation that a higher owngender share reduces marriage prospects due to higher competition and increased marital search costs within the relevant marriage market.

The regression results presented in Table 2 are based on a linear specification of Eq. (1). However, non-linear relationships between the gender composition in the field of study and the marriage market outcomes may be plausible as well. For example, the linear estimates may be driven by individuals who experienced extremely unbalanced gender compositions. For this purpose, I run specifications of Eq. (1) where the continuous own-gender share is replaced by a series of indicators for specific levels of the gender share. Results for this flexible specification of a nonlinear relationship between the student sex ratio and marriage market outcomes are shown in Fig. 5 and reveal a fairly linear pattern, in particular for the outcomes of 


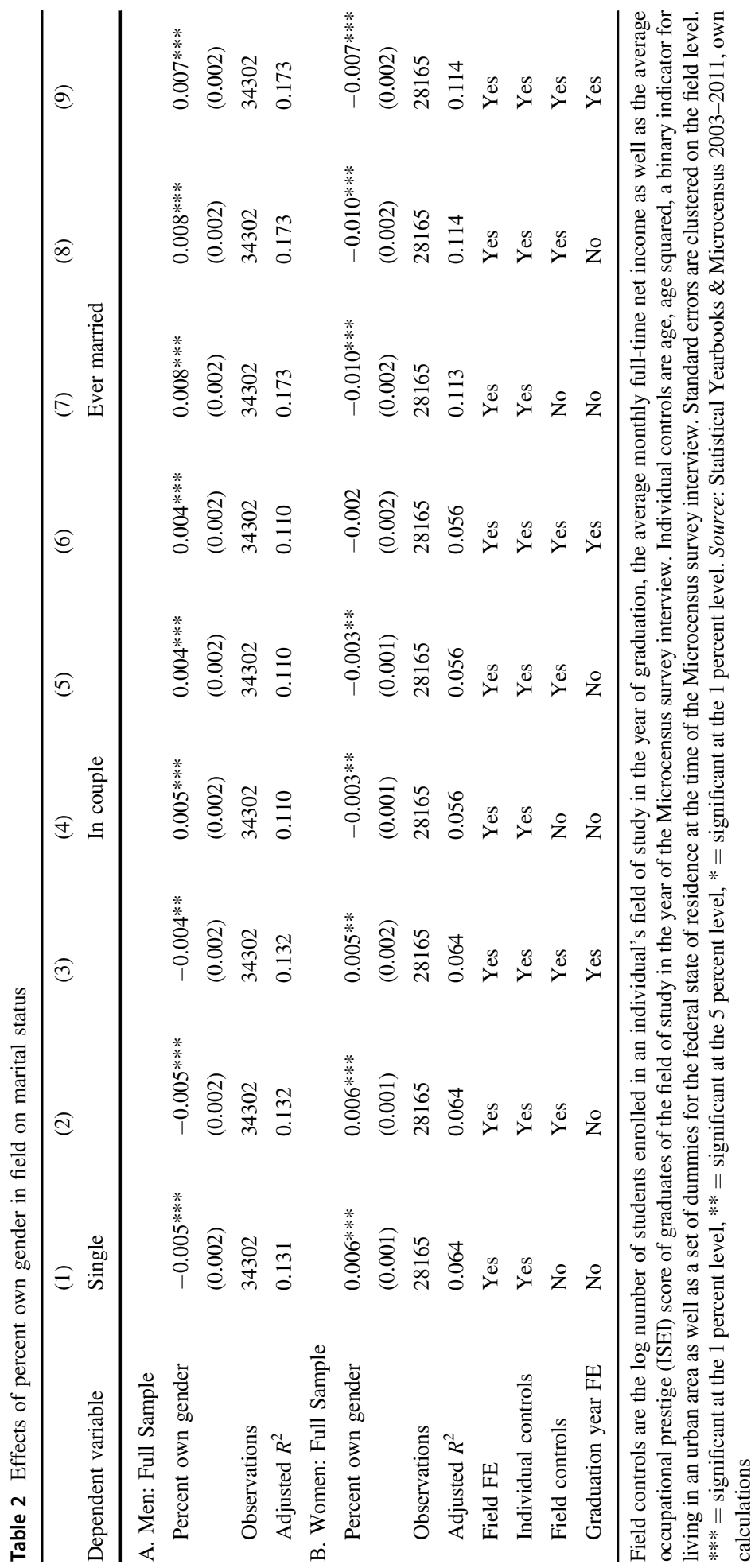




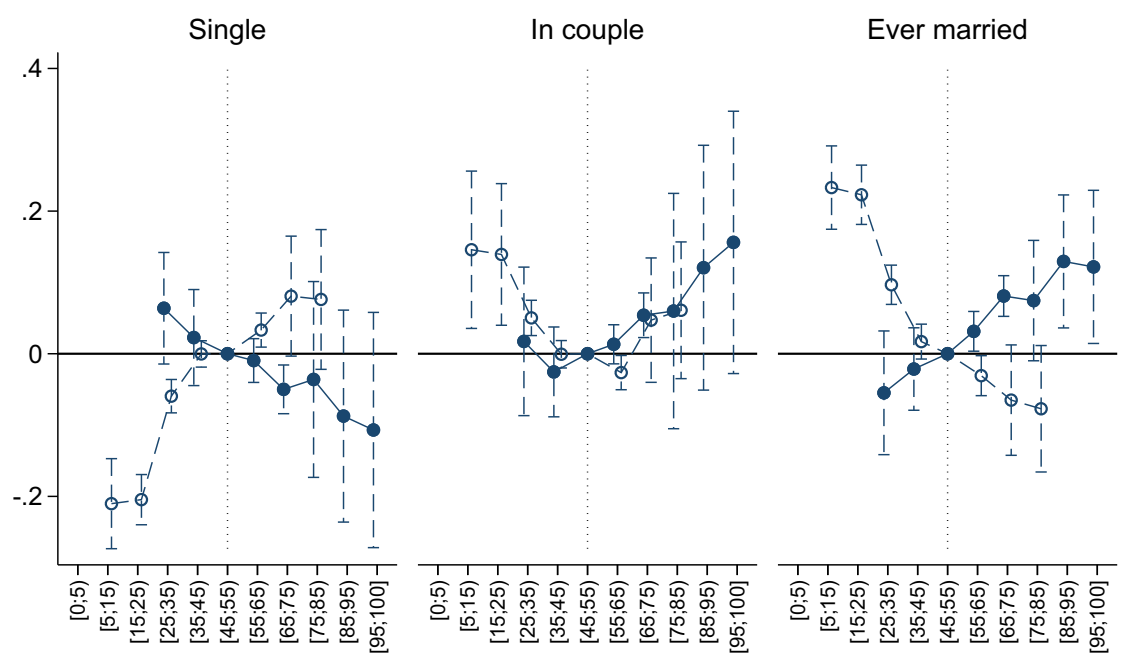

Percent own gender (bin dummies)

$\multimap$ Men $-\theta-$ Women

Fig. 5 Non-linear effects of percent own gender on marital status. This graph shows estimation results for the coefficient $\beta$ from six separate regressions of Eq. (1) replacing the linear effect of percent of own gender with a series of eleven dummies. Each scatter point indicates the point estimate for the respective bin dummy. The omitted category is percent own gender between 45 and 55 . The vertical whiskers indicate 95\% confidence intervals. Source: Statistical Yearbooks \& Microcensus 2003-2011, own calculations

remaining single and having ever been married. This means that the results are not driven by graduates from fields with highly unbalanced sex ratios but that also moderate deviations from a perfectly gender-balanced environment affect the marriage prospects of students.

\subsubsection{Effects on composition of couples}

The results discussed in the previous paragraph show that the own-gender share among university students within the field of study affects couple formation in general. I now turn to outcomes related to the composition of couples with respect to the level of education, i.e., whether a university graduate's partner has attained university education as well, and whether university-educated partners are from the same or from a different field of study. ${ }^{15}$

The results are displayed in Table 3. The estimates in Panel A for universityeducated men show that a higher own-gender share affects the margin of having a partner with completed university education (columns (1)-(3)). After including all controls and fixed effects a one percentage point higher male share on average significantly reduces the probability of having a partner holding a tertiary degree by

\footnotetext{
${ }^{15}$ The analysis is based on the full samples of university-educated men and women and the indicators take on the value of zero for single individuals not living with a partner in the household at the time of the Microcensus survey.
} 


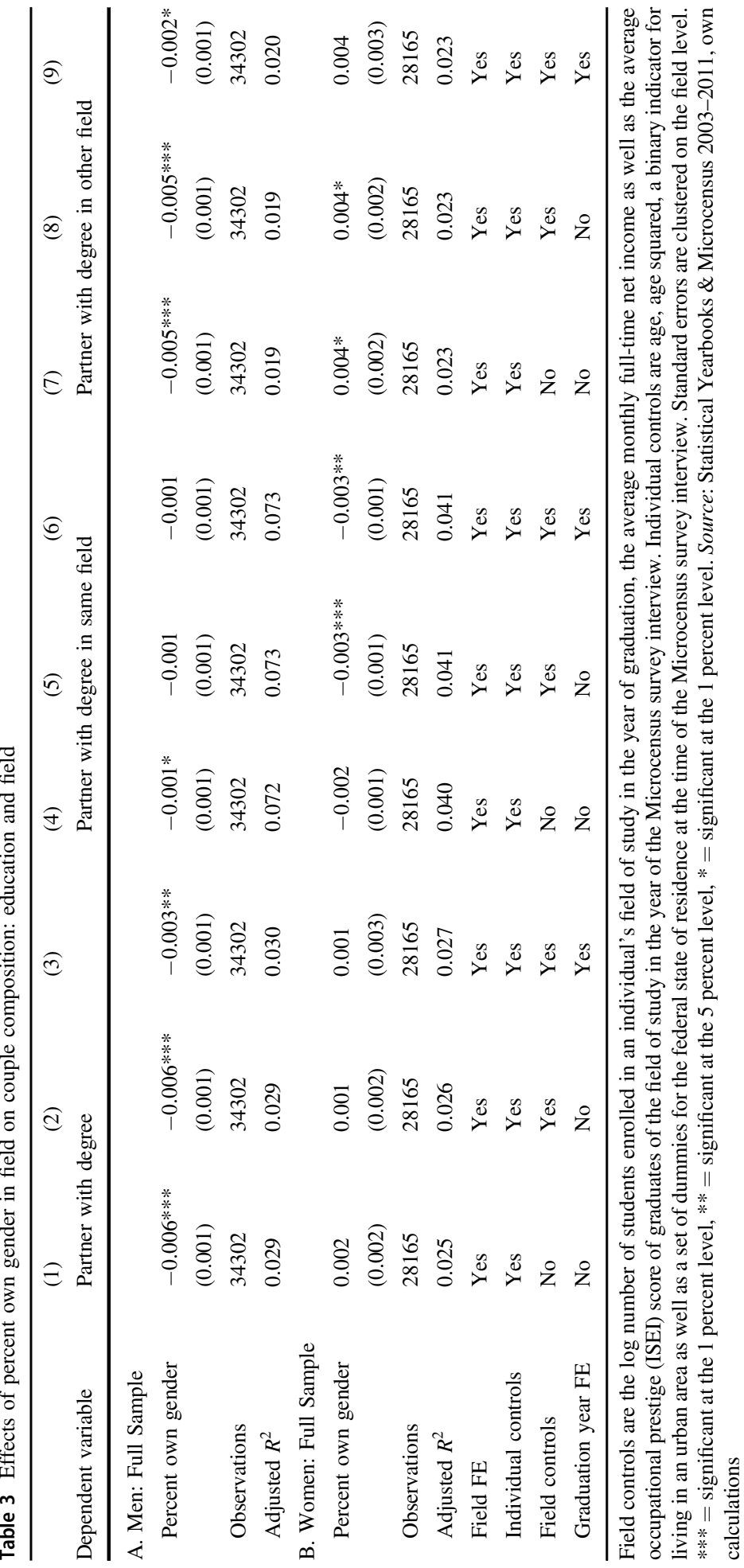




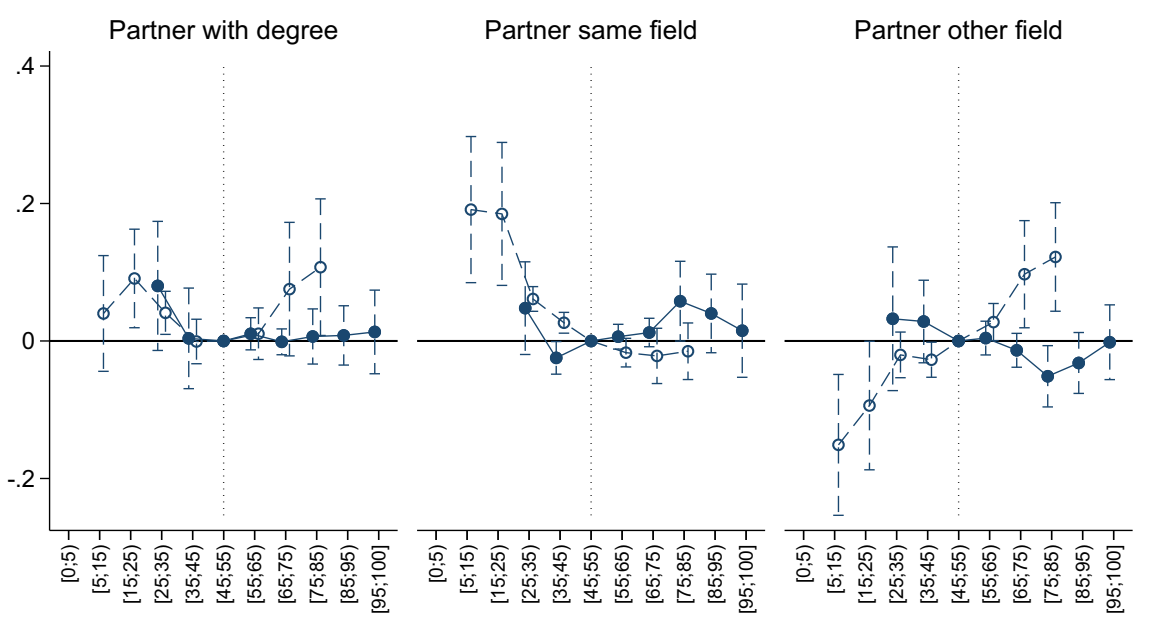

Percent own gender (bin dummies)

$\longrightarrow$ Men $-\theta-$ Women

Fig. 6 Non-linear effects of percent own gender on couple composition. This graph shows estimation results for the coefficient $\beta$ from six separate regressions of Eq. (1) replacing the linear effect of percent of own gender with a series of eleven dummies. Each scatter point indicates the point estimate for the respective bin dummy. The omitted category is percent own gender between 45 and 55 . The vertical whiskers indicate 95\% confidence intervals. Source: Statistical Yearbooks \& Microcensus 2003-2011, own calculations

0.3 percentage points $(0.8 \%$ at the mean). This finding is consistent with the interpretation that a higher percentage of the own gender among fellow students reduces the chances of meeting an opposite-gender partner within the university environment. Taking into account the partner's field of study, the results in columns (4)-(9) show that this result tends to affect both margins of finding a university-educated wife from the same or from a different field of study.

The results for non-linear specifications shown in Fig. 6 show that the impact is mainly driven by men who experienced a rather low male share (less than $50 \%$ of male students) during university education having a significantly higher probability of a within-field match compared to men who experienced a more balanced or predominantly male student gender composition. Given that a higher share of male students improves male students' overall success on the marriage market (see Table 2 ), the results on couple composition indicate that when men are more abundant within their field of study, they are apparently more likely to expand their search for a potential spouse outside the university environment. This implies that male graduates are also willing to "marry down" with respect to the level of education.

The results for women holding a university degree are shown in Panel B of Table 3. A higher female share of students during education does not significantly change the probability of women having a partner holding a university degree (columns (1)(3), but does significantly reduce the probability of having a partner from the same field of study (columns (4)-(6)). A one percentage point higher female share of students reduces the probability of a university-educated spouse (from the same field) 
by 0.3 percentage points (corresponding to $1.9 \%$ at the mean). The non-linear specification presented in Fig. 6 shows that women exposed to a very low own-gender share (below 25\%) are more likely to have a same-field partner than women who have experienced a more balanced gender composition.

This means that university educated women's partner search seems to be strongly affected by the gender composition of fellow students during university education. This is consistent with the notion that partner search costs on the marriage market are lower when being outnumbered by the opposite gender (Mansour and McKinnish, 2018). An increasing own-gender share implying reduced relative scarcity increases search costs and makes within-field mating less likely. In addition, these findings indicate that there are gender-specific preferences for marrying up or down the educational ladder. When the female share among fellow students is higher, making within-field partner search more costly and more difficult, an important alternative search pool seems to be the university environment more generally, including different fields of study. Hence, educated women seem to prefer to marry a spouse from the same educational level or remaining single over "marrying down" the educational ladder. ${ }^{16}$ At the same time, men are more likely to search for partners outside the university environment. This interpretation is consistent results shown in Table 5 for individuals' age at graduation and age at marriage among those in married couples. To the extent that the gender composition among fellow students affects partner search inside or outside the own field of study, the timing of graduation and consequently the age at marriage may at the margin be responsive to the length of partner search alongside other determinants of age at graduation and marriage. The results show that this relationship is different between men and women. While men graduate and leave earlier when the own-gender share is high women graduate later and stay for longer in the university environment (columns (1) to (3)). Also, a higher male share among fellow students slightly reduces age at marriage for men while women marry later when faced with a higher female share of students in the field of study.

\subsubsection{Meeting of spouses at university or at work?}

The interpretation of the results of the field-specific gender composition among university students so far relies on the idea that couples meet and match whilst at university, which is however not directly testable based on the available data. An alternative explanation could be forwarded with respect to work environments after graduation, given that graduating from a specific field of study typically prepares for careers in related occupations. Students of engineering will usually start careers as engineers while students of medicine will be working as doctors after having completed their university education. This means that work environments in specific occupations can be expected to be similarly gender-differentiated as the student gender composition of closely related fields of study. Hence, in addition to affecting the probability of encountering potential opposite-gender spouses at university the

\footnotetext{
${ }^{16}$ Another mechanism behind these results could be the fact that the overall female share of students has always been below $50 \%$ for the entire sample though increasing over time (see Fig. 3). Hence, female students may be over-represented in some fields, but are always outnumbered on aggregate, making the wider university environment more attractive for partner search.
} 
student gender composition may also have an effect on the frequency of meeting opposite-gender colleagues and co-workers. Lacking information on whether observed partnerships of university graduates have actually been initiated during university, I exploit the information on spouses' year of graduation.

If the interpretation that the university environment represents an important marriage market is relevant this implies that the graduation year among universityeducated spouses is the same or very close. On average, $44 \%$ of couples where both partners hold a university degree have graduated at about the same time, i.e., within at most 1 year (see Table 1). Indeed, the results in columns (1)-(3) of Table 4 show that a higher percentage of the own gender among students in the field significantly reduces the probability that the partner's year of graduation is similar for women, but not for men. A one percentage point higher female share reduces the probability of the spouses' similarity in the year of graduation by 0.5 percentage points, corresponding to an effect of about $1.9 \%$ at the mean. ${ }^{17}$

While this result supports the interpretation that an unbalanced student gender composition enhances couple initiation at university for the scarcer gender, the related gender composition of work environments may be of additional relevance for "partner search on the job" (McKinnish, 2007). This mechanism would imply that spouses are similar with respect to the industry and occupation. The share of spouses working in the same industry or occupation is between $10 \%$ and $15 \%{ }^{18}$ Columns (4)-(6) of Table 4 show that indeed a higher percentage of the own gender significantly increases the probability of having a partner working in the same industry sector for men while the estimate is negative and only marginally significant for women. This supports the notion that men graduating from male-dominated fields are more likely to meet their spouse at work. However, as shown in columns (7)-(9), at the same time the outcome of having a spouse working in the same occupation is not significantly affected by a higher share of male students. This result indicates that men are likely to meet their partner within their work environment but among women performing different tasks, arguably not requiring a university education given that the results on marital status and couple composition have shown that men are more more likely to live with a partner with a lower level of education (see Tables 2 and 3) (Table 5).

\subsection{Additional results and robustness checks}

\subsubsection{Choice of field of study driven by marriage market considerations?}

In order to address potential concerns regarding selection into fields of study being mainly driven by marriage market rather than labor market considerations, I present estimation results exploiting field-specific information on admission restriction rules.

\footnotetext{
17 Note that the number of observations in columns (1)-(3) of Table 4 is below the sample size of the male and female couple samples since the graduation year of the spouse is only observed for couples where both partners are university graduates. This the case for $47 \%$ of men and $69 \%$ of women living in couple households (see Table 1).

18 Summary statistics are presented in Table 1. For this analysis, I employ 2-digit categories according to the Statistical Office's classification of industries and classification of occupations respectively.
} 


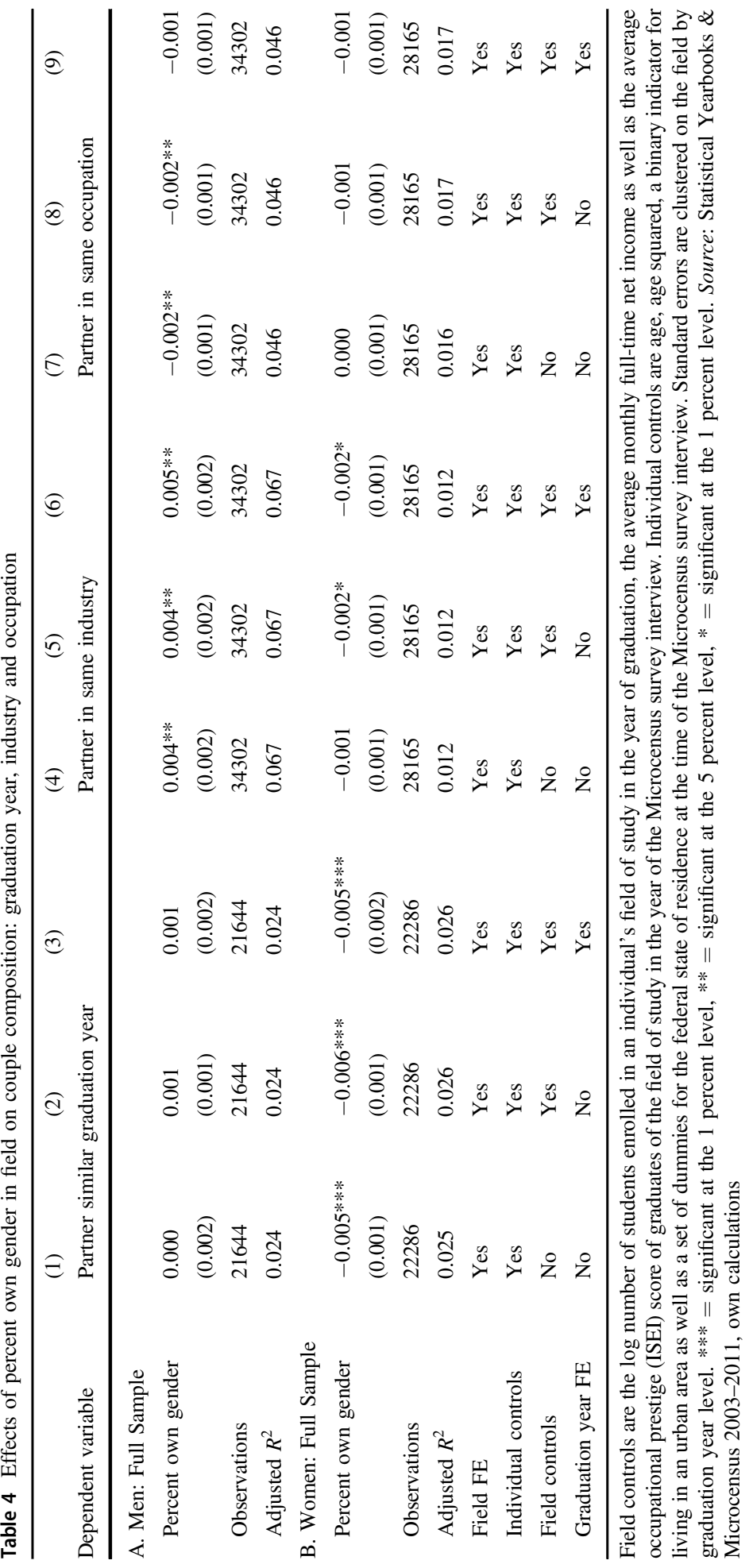


Table 5 Effects of percent own gender in field on age at graduation and marriage

(1) (2) (3) (4) (5)

(5)

(6)

Dependent variable Age at graduation Age at marriage

\begin{tabular}{lllllll}
\hline A. Men: Full Sample & & & & & & \\
Percent own gender & $-0.329^{* * *}$ & $-0.304^{* * *}$ & $-0.201^{* * *}$ & $-0.137^{* * *}$ & $-0.090^{* *}$ & $-0.080^{*}$ \\
& $(0.046)$ & $(0.036)$ & $(0.039)$ & $(0.046)$ & $(0.044)$ & $(0.045)$ \\
Observations & 34302 & 34302 & 34302 & 3096 & 3096 & 3096 \\
Adjusted $R^{2}$ & 0.204 & 0.253 & 0.322 & 0.074 & 0.079 & 0.082 \\
B. Women: Full Sample & & & & & & \\
Percent own gender & $0.356^{* * *}$ & $0.322^{* * *}$ & $0.207 * * *$ & $0.341^{* * *}$ & $0.280^{* * *}$ & $0.251^{* *}$ \\
& $(0.056)$ & $(0.047)$ & $(0.040)$ & $(0.114)$ & $(0.089)$ & $(0.095)$ \\
Observations & 28165 & 28165 & 28165 & 2042 & 2042 & 2042 \\
Adjusted $R^{2}$ & 0.254 & 0.335 & 0.382 & 0.110 & 0.132 & 0.136 \\
Field FE & Yes & Yes & Yes & Yes & Yes & Yes \\
Individual controls & Yes & Yes & Yes & Yes & Yes & Yes \\
Field controls & No & Yes & Yes & No & Yes & Yes \\
Graduation year FE & No & No & Yes & No & No & Yes \\
\hline
\end{tabular}

Field controls are the log number of students enrolled in an individual's field of study in the year of graduation, the average monthly full-time net income as well as the average occupational prestige (ISEI) score of graduates of the field of study in the year of the Microcensus survey interview. Individual controls are age, age squared, a binary indicator for living in an urban area as well as a set of dummies for the federal state of residence at the time of the Microcensus survey interview. Standard errors are clustered on the field level. $* * *=$ significant at the 1 percent level, $* *=$ significant at the 5 percent level, * = significant at the 1 percent level. Source: Statistical Yearbooks \& Microcensus 2003-2011, own calculations

Enrolling in university education in a field where admission is restricted may not fully rule out the possibility that the motivation for choosing the respective field is driven by marriage market considerations. However, I argue that this is much less likely since enrolling in a restricted field is costly from an individual's point of view. First, some applicants may have to wait one or more semesters before they are actually admitted. Second, particularly the central level restriction typically implies that the choice of specific university is beyond the control of the individual applicant. Both aspects substantially increase the opportunity costs of choosing a restricted field of study, making it much more likely that the motivation is primarily (if not only) driven by labor market considerations. For this reason, I run regressions where the sample is restricted to individuals who graduated from a field of study where admission was restricted to large extent, indicated by the percentage of admissionrestricted universities, 5 years prior to graduation. The results are shown in Figs. 7 and 8 and indicate that the effects of gender composition in restricted fields are very much in line with the baseline results.

In Germany, admission to university education in specific fields can either be restricted at the central (federal) level or at the local (university) level. Central 


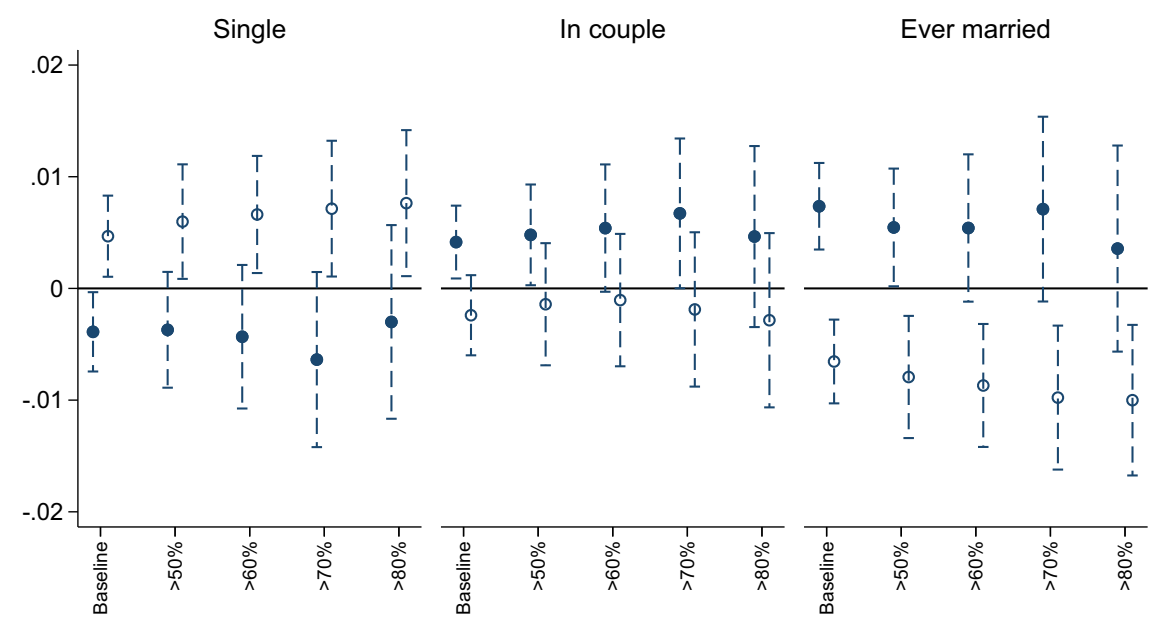

Extent of admission restriction

- Men o Women

Fig. 7 Effects of percent own gender on marital status for admission-restricted fields. This graph shows estimation results for the coefficient $\beta$ from 30 separate regressions of Eq. (1) for alternative sub-samples with respect to the extent of field-specific admission restrictions 5 years prior to individual graduation. The baseline estimates show the respective results from Table 2 and can be compared to the estimates for samples of individuals whose field was characterized by a level of admission restriction of more than 50\%, $60 \%, 70 \%$, or $80 \%$. Each scatter point indicates the respective point estimate for percent of own gender in the field. The vertical whiskers indicate $95 \%$ confidence intervals. Source: Statistical Yearbooks \& Microcensus 2003-2011, own calculations

restriction of admission implies that only applicants whose overall score in their secondary school leaving examination (Abitur) passes a minimum threshold, which differs across fields and over time. ${ }^{19}$ The main purpose is to allocate applicants for a place at university in fields where demand exceeds available capacities which mainly, but not exclusively, applies to fields in Medical Sciences. In addition, individual universities may also define their own admission restriction rules for specific fields. For this purpose, I compile administrative information on annual fieldspecific admission restrictions from the German Rector's Conference (Hochschulrektorenkonferenz), an umbrella organization of German universities. The dataset is based on annual publications listing the situation of admission restriction (free admission, local restriction or central restriction) for each field at each university in Germany. This allows me to compute an index of admission restriction ranging from zero (free admission) and $100 \%$ (admission fully restricted). Values in between give the percentage of German universities where admission to the respective field is restricted in a given year. Over the period under consideration between 1977 and 2011, the extent of admission restriction varies substantially both across fields and within fields over time, see Figs. 16 and 17.

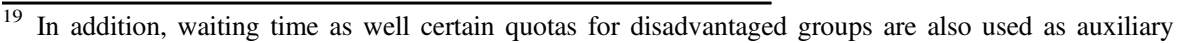
criteria. 


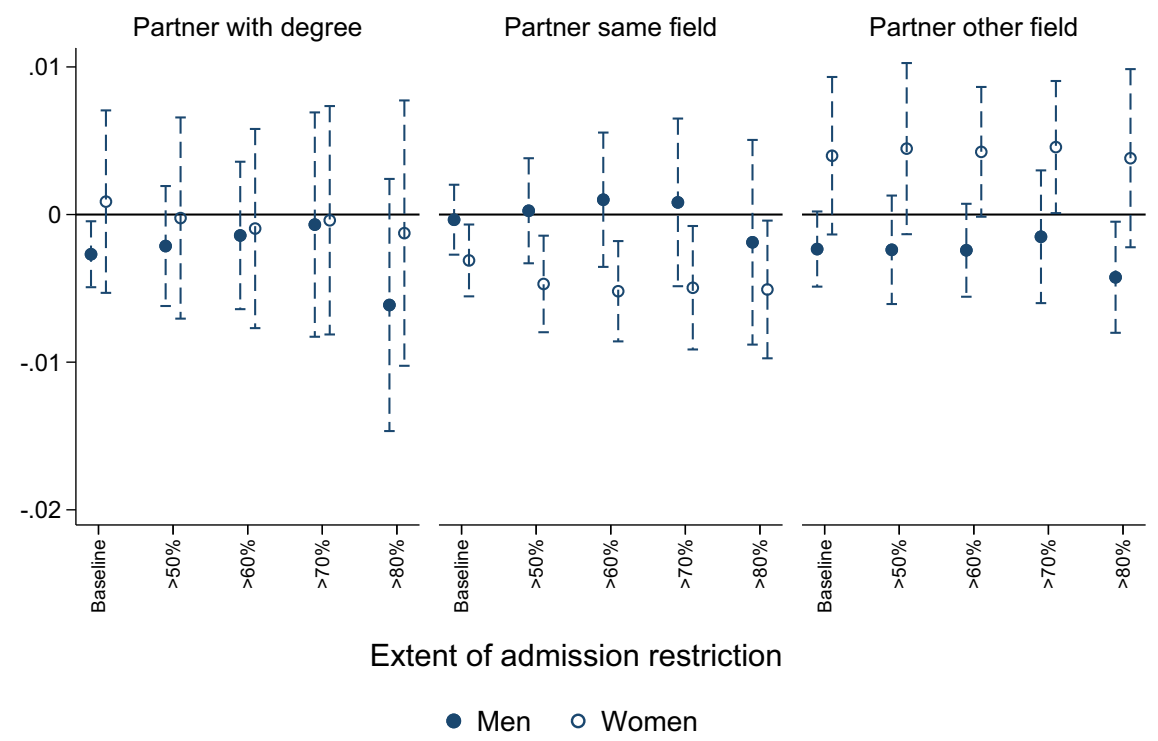

Fig. 8 Effects of percent own gender on couple composition for admission-restricted fields. This graph shows estimation results for the coefficient $\beta$ from 30 separate regressions of Eq. (1) for alternative subsamples with respect to the extent of field-specific admission restrictions 5 years prior to individual graduation. The baseline estimates shows the respective results from Table 3 and can be compared to the estimates for samples of individuals whose field was characterized by a level of admission restriction of more than $50 \%, 60 \%, 70 \%$, or $80 \%$. Each scatter point indicates the respective point estimate for percent of own gender in the field. The vertical whiskers indicate $95 \%$ confidence intervals. Source: Statistical Yearbooks \& Microcensus 2003-2011, own calculations

\subsubsection{Placebo gender composition by randomly assigning the field of study}

In order to further corroborate the validity of the baseline estimation results, I run regressions with placebo treatments by randomly assigning the field of study while keeping the year of graduation fixed. This exercise is repeated 10,000 times for each outcome as well as for the samples of men and women separately and yields distributions of the coefficient estimates ( $\beta$ in Eq. (1)). The results are shown in Figs. 18 and 19. The vertical dashed lines indicate the point estimates from the baseline regression results presented in Tables 2 and 3. In almost all cases, the baseline point estimate is significantly different and more pronounced than the distribution of placebo treatment effects except for those outcomes where the baseline effect is anyway not significantly different from zero. What is reassuring for the analysis, is the fact that the baseline estimate is usually significantly outside the distribution of placebo effects. This indicates that the actually experienced gender composition during university education has more pronounced impacts on marriage market outcomes of university graduates.

\subsubsection{Lagged gender composition with respect to graduation year}

In the baseline specification, the gender composition assigned to each individual is based on the exact field of study and the year of graduation in that field. However, a university graduate's field-specific gender composition reflecting marital search 


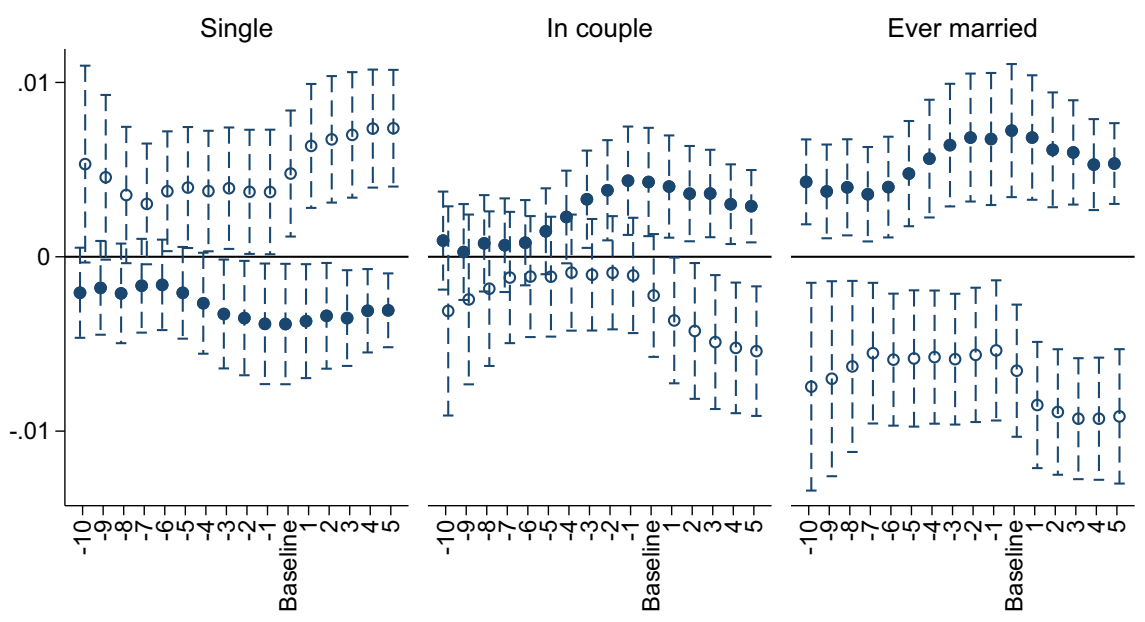

Years to/since graduation

- Men o Women

Fig. 9 Effects of percent own gender on marital status for different lags of graduation year. This graph shows estimation results for the coefficient $\beta$ from 96 separate regressions of Eq. (1) for alternative definitions of the field-specific gender composition's timing, employing lags $l \in\{-10, \ldots,+5\}$ with respect to an individual's year of graduation $g$. Zero years before graduation is the baseline specification shown in A of Table 2. Each scatter point indicates the respective point estimate for percent own gender. The vertical whiskers indicate 95\% confidence intervals. Source: Statistical Yearbooks \& Microcensus 2003-2011, own calculations

conditions may not be the one that prevailed in the year of graduation, i.e., at the end of education, but rather the one at the beginning of or during the course of study. Unfortunately, the year of starting university education is not available in the Microcensus data. That is why I present regression results assigning the gender composition of students between one and ten years before the year of graduation. ${ }^{20}$ The results are presented in Figs. 9 and 10 and are very similar to the baseline specifications (equal to zero years before graduation). This is not surprising given the fact that, while the gender composition has changed substantially in some fields of study over several decades, the year-by-year levels are highly correlated. However, it turns out that those results assigning the gender composition between zero and 5 years before graduation are more pronounced than those assigning the gender composition more than 5 years prior to graduation. This is consistent with a typical duration of university education of about 5 years.

\section{Conclusions}

This paper studies how the gender composition among university students by field of study affects marriage market outcomes of university graduates in Germany. Using rich

\footnotetext{
${ }^{20}$ For example, in the baseline specification an individual who graduated in 2000 is assigned the respective field-specific gender share in that year. In the alternative specifications the individual is assigned the gender share that prevailed in 1999, 1998, and so on.
} 


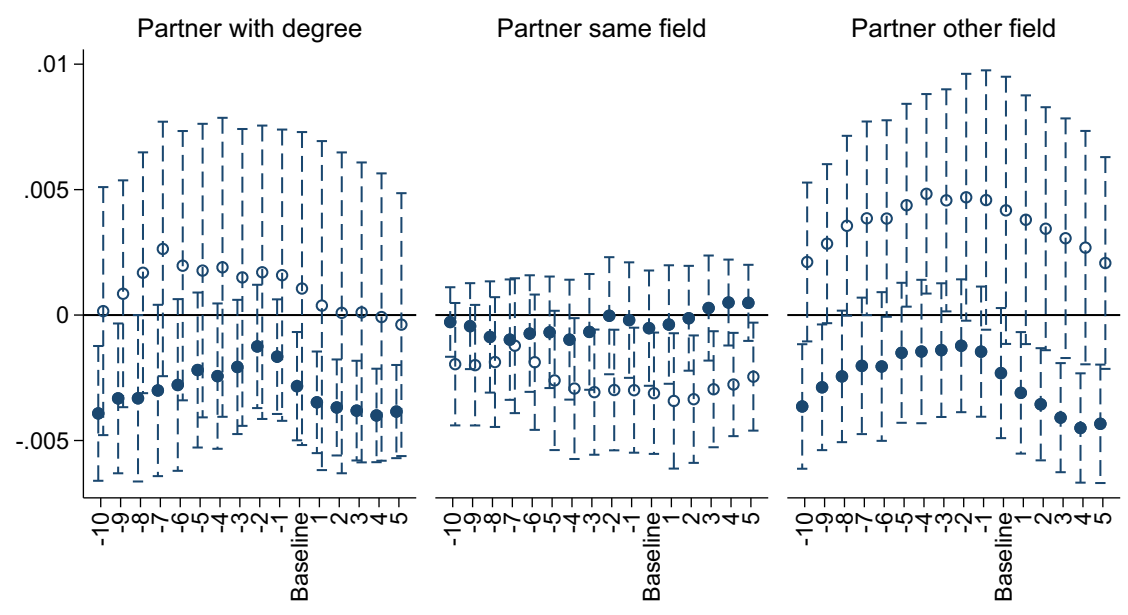

Years to/since graduation

- Men o Women

Fig. 10 Effects of percent own gender on couple composition for different lags of graduation year. This graph shows estimation results for the coefficient $\beta$ from 96 separate regressions of Eq. (1) for alternative definitions of the field-specific gender composition's timing, employing lags $l \in\{-10, \ldots,+5\}$ with respect to an individual's year of graduation $g$. Zero years before graduation is the baseline specification shown in A of Table 3. Each scatter point indicates the respective point estimate for percent own gender. The vertical whiskers indicate 95\% confidence intervals. Source: Statistical Yearbooks \& Microcensus 2003-2011, own calculations

data from the German Microcensus combined with aggregate information for more than 40 fields of study over the period 1977-2011, I exploit over-time variation in the gender composition within fields of study. The main findings of the paper show that the gender composition of fellow students within the field of study experienced during education has significant impacts on marriage market outcomes for university graduates with distinct gender differences. First, a higher own-gender share of students negatively affects marriage market opportunities for women by increasing the probability of remaining single and reducing marriage rates, while the opposite is true for men. Second, an imbalanced student sex ratio significantly affects the composition of couples in terms of education and the field of study. A higher share of the own gender increases the probability of having an opposite-sex partner from a different field of study for women. At the same time, men are more likely to marry down with respect to educational status, while women rather have a partner with the same level of education.

Overall, the results of this study are in line with gender identity norms with respect to couple formation, implying that women typically prefer to "marry up" the socioeconomic ladder (Bertrand et al., 2015). These findings imply that changes in the gender composition of students may have implications for the socio-demographic composition of societies since we may expect increases in assortative mating of couples when the formation of same-field relationships is enhanced in maledominated fields. This may have longer-run impacts on income inequality and intergenerational mobility. At the same time, further increases in the female share of students in fields already dominated by women may increase the number of 
university-educated women remaining single (longer), which may, in turn, have negative implications for fertility among high-skilled women.

Finally, the causal interpretation of the results presented in this paper should account for the necessary assumptions given the institutional setting as well as the availability of data. In particular, determinants of the student gender composition may also affect students' marriage market prospects and preferences. For example, over the period under investigation, student gender composition has been changing alongside many cultural and social norms, particularly with respect to gender roles including women's educational attainment and labor force participation. The empirical model in this study accounts for these factors by controlling for year of graduation fixed effects, which absorb any societal and institutional determinants of both student gender composition and marriage market prospects that are uniform for students of the same graduation cohorts across all fields of study, but not necessarily between fields. Similarly, conditioning on fixed effects for field of study takes into account differences in unobserved characteristics of students with respect to gender norms between fields of study. However, the interpretation of the results of this paper rely on the assumption that these are time-invariant, while gradual shifts in unobserved characteristics of marginal students entering fields may change the composition within field over time. Therefore, I acknowledge that absent quasiexperimental variation in student gender composition as well as data limitations, I cannot rule out that these factors may vary by field of study, such that the presented estimates may be biased upwards to some extent. Studying the role of these secular trends for marriage market outcomes among university-educated individuals should be addressed by future research.

Acknowledgements I am grateful to Christian Bredemeier, Arnaud Chevalier, Deborah Cobb-Clark, Karina Doorley, Benjamin Elsner, Carlo Fiorio, Dan Hamermesh, Ingo Isphording, Andreas Lichter and Ulf Zölitz, seminar participants at IZA and U Cologne as well as participants of the 19th Annual Meetings of the SOLE in Arlington, the 30th Annual Conference of the ESPE and the IZA Gender and Family Economics Workshop for helpful comments and suggestions. Lea Drilling, Johannes Hermle and Rafael Suchy provided excellent research assistance. Moreover, I am grateful to the data service of the International Data Service Center of IZA.

Funding Open Access funding enabled and organized by Projekt DEAL.

Conflict of interest The author declares no competing interests

Publisher's note Springer Nature remains neutral with regard to jurisdictional claims in published maps and institutional affiliations.

Open Access This article is licensed under a Creative Commons Attribution 4.0 International License, which permits use, sharing, adaptation, distribution and reproduction in any medium or format, as long as you give appropriate credit to the original author(s) and the source, provide a link to the Creative Commons license, and indicate if changes were made. The images or other third party material in this article are included in the article's Creative Commons license, unless indicated otherwise in a credit line to the material. If material is not included in the article's Creative Commons license and your intended use is not permitted by statutory regulation or exceeds the permitted use, you will need to obtain permission directly from the copyright holder. To view a copy of this license, visit http://creativecommons.org/licenses/by/4.0/. 


\section{Appendix}

Figures 11, 12, 13, 14, 15, 16, 17, 18 and 19. Table 6.

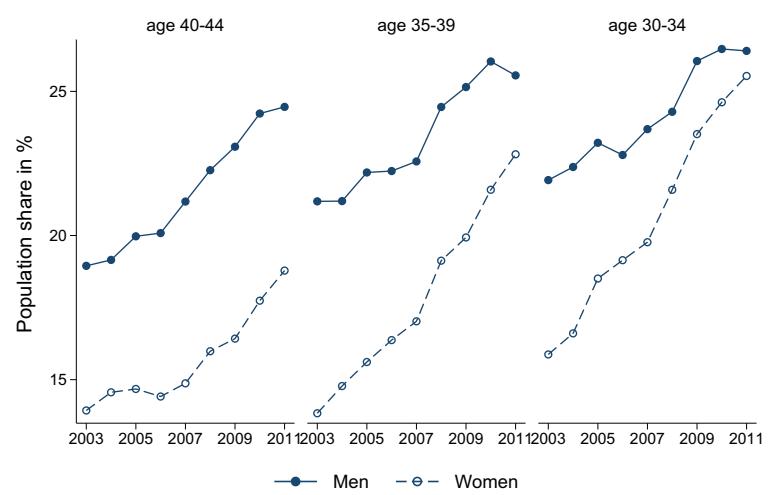

Fig. 11 University education by gender and age. This graph shows the population share of individuals holding a university degree by gender and age groups over between 2003 and 2011. Source: Microcensus 2003-2011, own calculations

Men

Age at completion of education

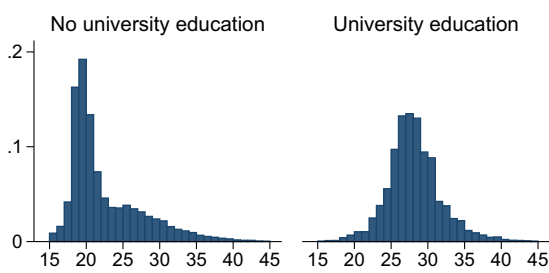

Age at marriage

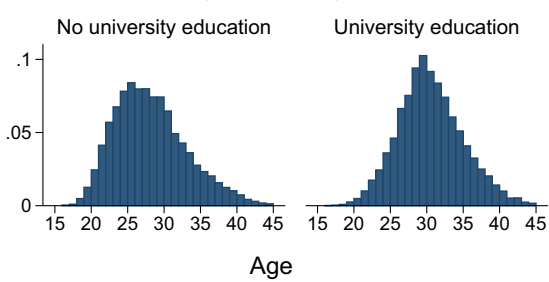

Women

Age at completion of education

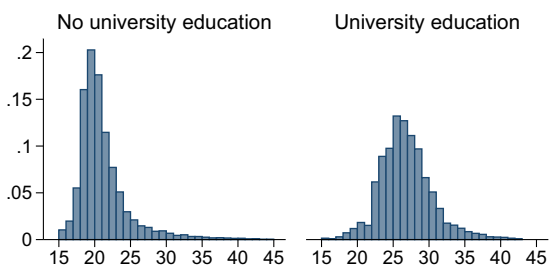

Age at marriage

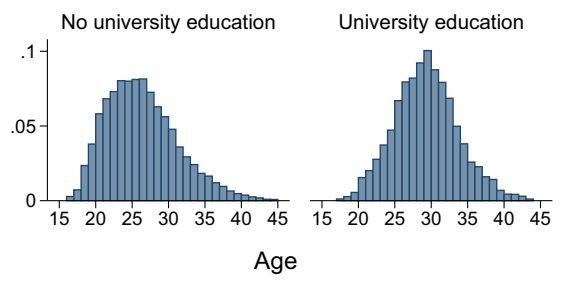

Fig. 12 Age at completing education and marriage. This graph shows the distribution of individuals' age at completing education and age at marriage by gender and level of education. Source: Microcensus 2003-2011, own calculations 


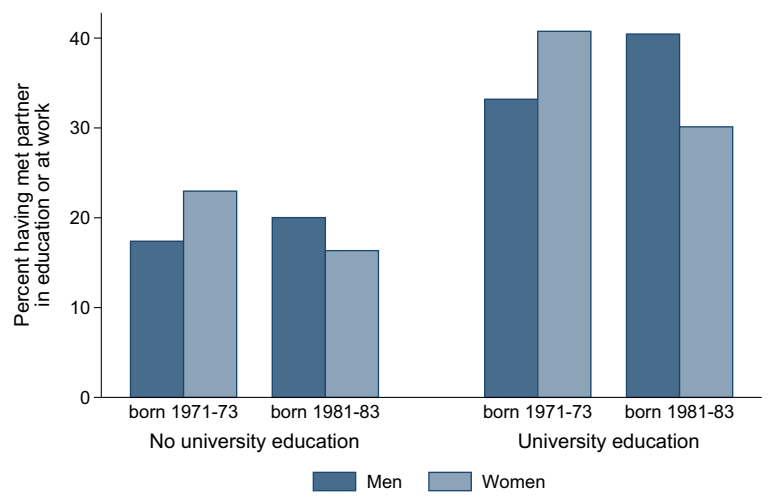

Fig. 13 Meeting of partner in education or at work. This graph shows the fraction of couples who state that they have met in school, during education or at the workplace by level of education and birth cohort. Source: Panel Analysis of Intimate Relationships and Family Dynamics (pairfam), wave 1 (2008/2009), own calculations

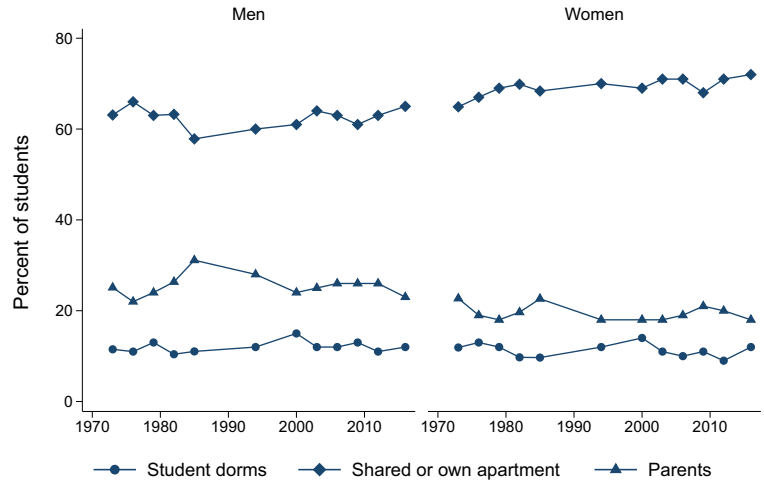

Fig. 14 Form of housing among university students in Germany. This graph shows the percentage of university students (by gender) living in different forms of housing over time. Source: Social Survey of German Student Services (Sozialerhebung Deutsches Studierendenwerk), own calculations 
Men

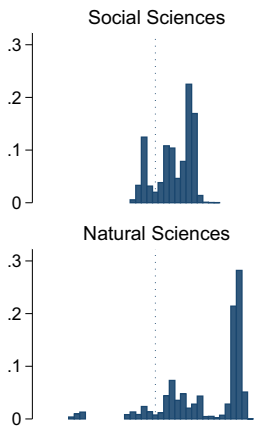

Engineering
Human Sciences

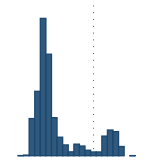

Medical Sciences

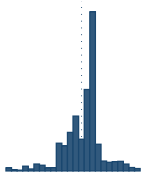

Arts

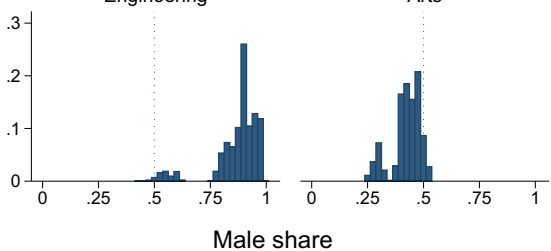

Women
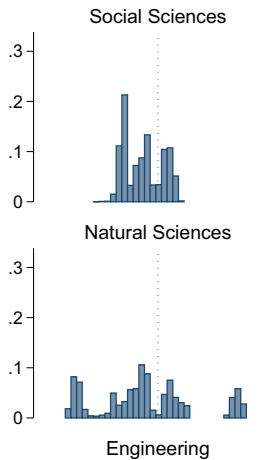

Medical Sciences

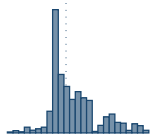

Arts

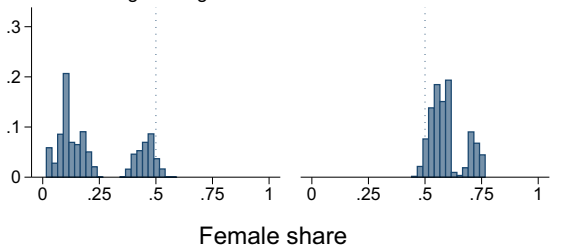

Fig. 15 Distribution of female share within field of study by field group. This histogram graph shows the distribution of the gender share among students within field of study during university education by field groups. The vertical dashed lines indicate a perfectly balanced gender composition with a female share of 50\%. Source: Statistical Yearbooks \& Microcensus 2003-2011, own calculations

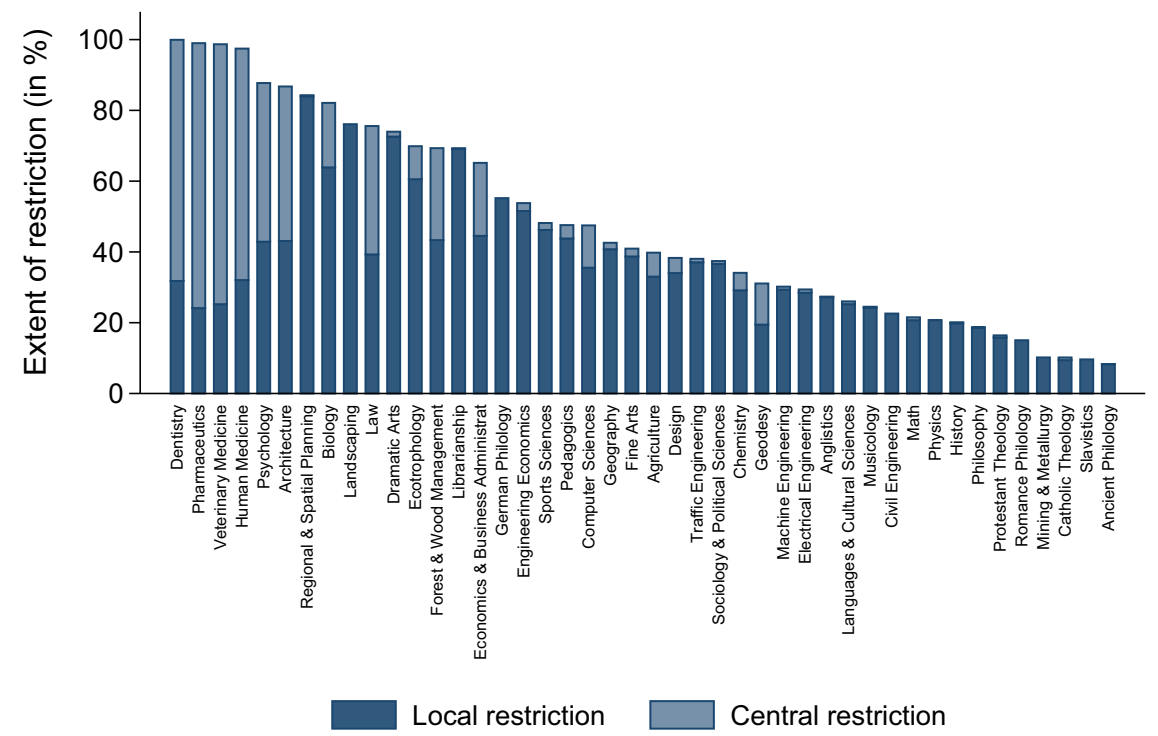

Fig. 16 Average level of admission restriction by field of study. This bar graph shows the mean percentage of German universities where admission to university education is restricted (centrally or locally) over the period 1977-2011 by field of study. Source: German Rectors' Conference (Hochschulrektorenkonferenz, HRK), own calculations 


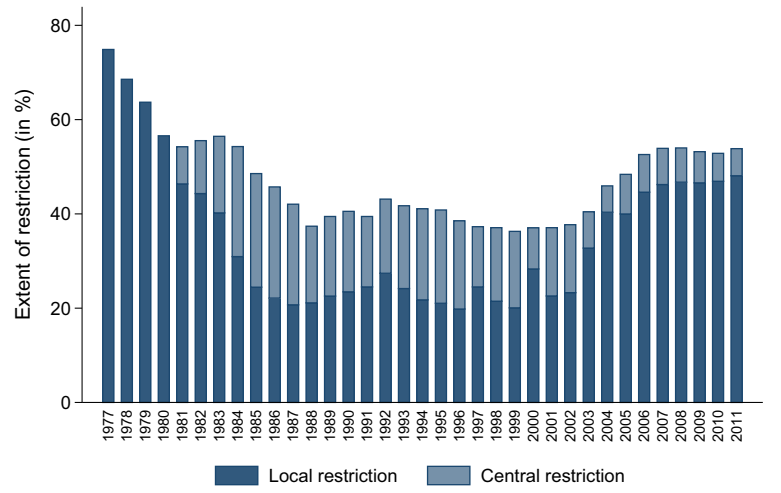

Fig. 17 Average level of admission restriction by year. This bar graph shows the mean percentage of German universities where admission to university education is restricted (centrally or locally) for all fields of study by year. Source: German Rectors' Conference (Hochschulrektorenkonferenz, HRK), own calculations
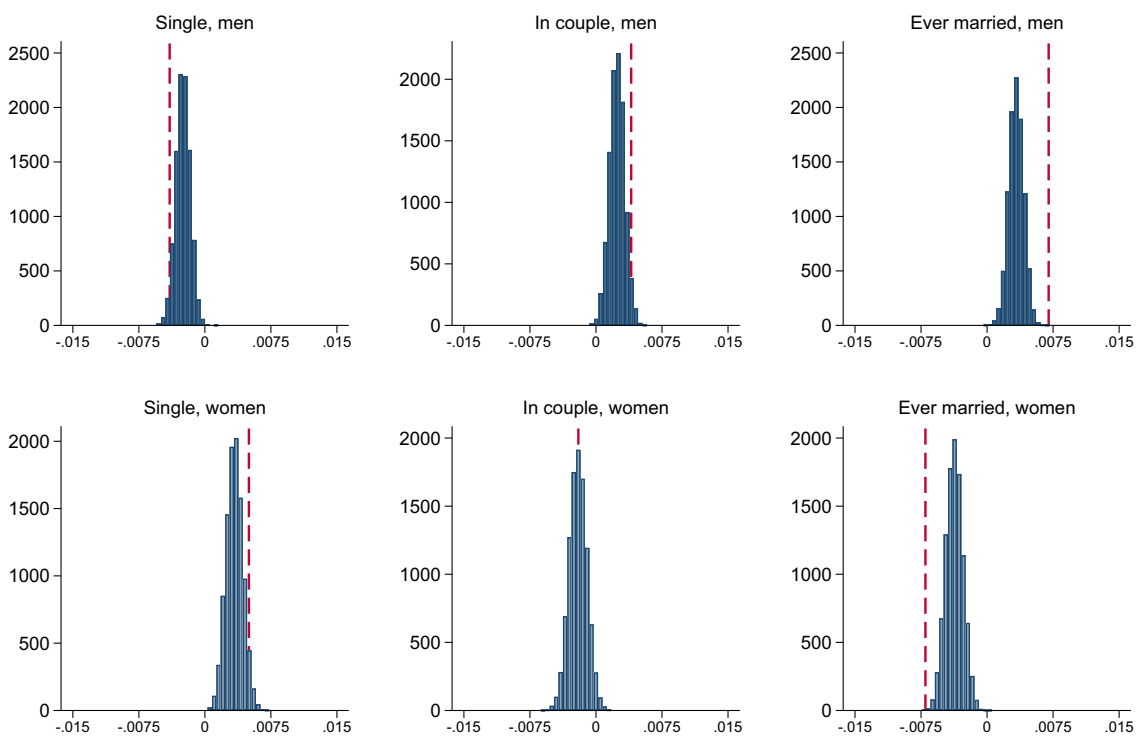

Fig. 18 Effects of percent own gender on marital status for randomly assigned field. This graph shows the frequency distribution of estimation results for the coefficient $\beta$ in Eq. (1) from 10,000 replications (per outcome and sample) when randomly assigning the field of study to individual observations and holding the year of graduation fixed. The dashed vertical line indicates the estimate of the baseline estimates as shown in Table 2. Source: Statistical Yearbooks \& Microcensus 2003-2011, own calculations 

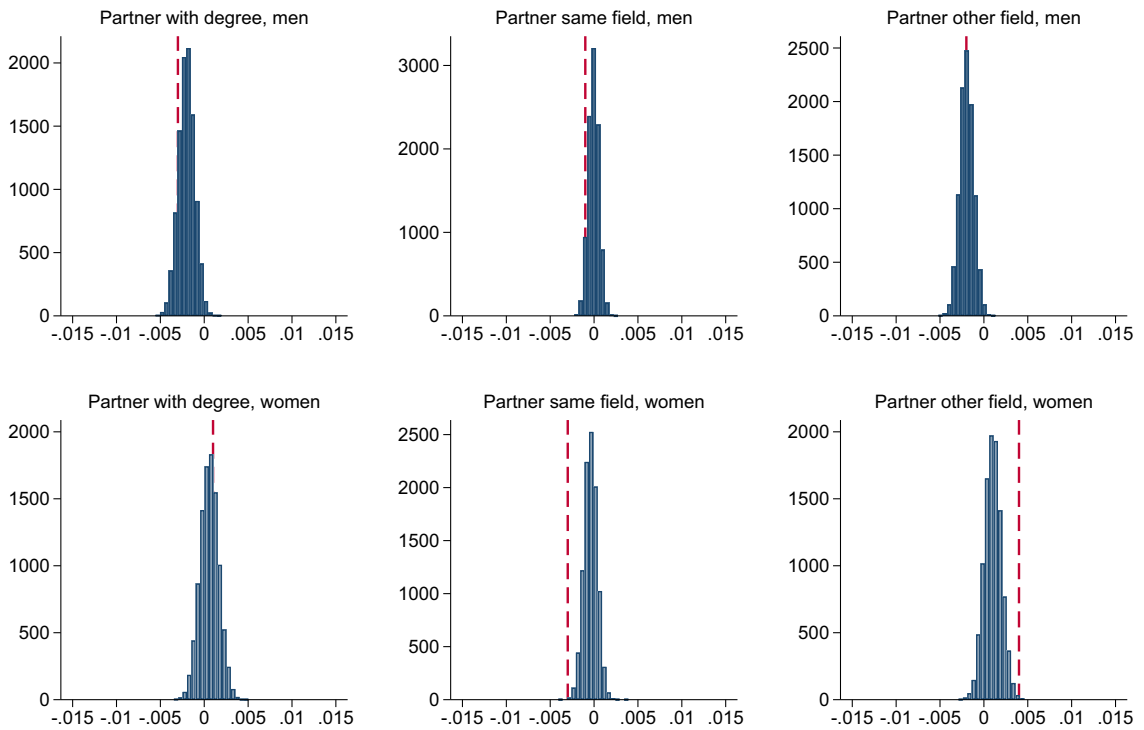

Fig. 19 Effects of percent own gender on couple composition for randomly assigned field. This graph shows the frequency distribution of estimation results for the coefficient $\beta$ in Eq. (1) from 10,000 replications (per outcome and sample) when randomly assigning the field of study to individual observations and holding the year of graduation fixed. The dashed vertical line indicates the estimate of the baseline estimates as shown in Table 3. Source: Statistical Yearbooks \& Microcensus 2003-2011, own calculations

Table 6 Gender composition by field of study

\begin{tabular}{|c|c|c|c|c|c|}
\hline \multirow{2}{*}{$\begin{array}{l}\text { Field group } \\
\text { Field }\end{array}$} & \multicolumn{2}{|c|}{ Percent female } & \multicolumn{3}{|c|}{ Observations } \\
\hline & Mean & SD & Men & Women & Total \\
\hline Social Sciences & 42.4 & 8.2 & 11,001 & 10,106 & 21,107 \\
\hline Law & 45.2 & 3.2 & 1673 & 1815 & 3488 \\
\hline Economics and Business & 37 & 4.4 & 7227 & 5644 & 12,871 \\
\hline $\begin{array}{l}\text { Sociology and Political } \\
\text { Sciences }\end{array}$ & 54.8 & 1.8 & 2101 & 2647 & 4748 \\
\hline Human Sciences & 69 & 8.7 & 2939 & 9200 & 12,139 \\
\hline $\begin{array}{l}\text { Languages and Cultural } \\
\text { Sciences }\end{array}$ & 66.6 & 1.8 & 61 & 174 & 235 \\
\hline Protestant Theology & 52.4 & 5 & 63 & 73 & 136 \\
\hline Catholic Theology & 45.6 & 3.9 & 86 & 69 & 155 \\
\hline Pedagogics & 72.1 & 2.7 & 1768 & 6379 & 8147 \\
\hline Philosophy & 40.1 & 1.7 & 242 & 162 & 404 \\
\hline Psychology & 69.4 & 4.8 & 148 & 498 & 646 \\
\hline History & 44.1 & .8 & 132 & 154 & 286 \\
\hline Librarianship & 57.5 & 3.1 & 140 & 344 & 484 \\
\hline Ancient Philology & 54.3 & 2.5 & 15 & 39 & 54 \\
\hline Anglistics & 71.4 & 1.1 & 89 & 488 & 577 \\
\hline Romance Philology & 78.1 & 1.2 & 12 & 114 & 126 \\
\hline Slavistics & 74.2 & 2.5 & 44 & 148 & 192 \\
\hline
\end{tabular}


Table 6 continued

\begin{tabular}{|c|c|c|c|c|c|}
\hline \multirow{2}{*}{$\begin{array}{l}\text { Field group } \\
\text { Field }\end{array}$} & \multicolumn{2}{|c|}{ Percent female } & \multicolumn{3}{|c|}{ Observations } \\
\hline & Mean & $\mathrm{SD}$ & Men & Women & Total \\
\hline German Philology & 72.4 & 2.6 & 139 & 558 & 697 \\
\hline Natural Sciences & 32.7 & 20.8 & 5128 & 2803 & 7931 \\
\hline Math & 42.8 & 3.5 & 429 & 335 & 764 \\
\hline Agriculture & 37.6 & 4.4 & 324 & 214 & 538 \\
\hline Sports Sciences & 43.5 & 1.5 & 165 & 166 & 331 \\
\hline Computer Sciences & 13.8 & 1.5 & 2189 & 367 & 2556 \\
\hline Physics & 12.8 & 2.9 & 646 & 105 & 751 \\
\hline Chemistry & 33.6 & 5.1 & 379 & 266 & 645 \\
\hline Biology & 56.7 & 3.2 & 334 & 607 & 941 \\
\hline Geography & 41.1 & 2.8 & 299 & 263 & 562 \\
\hline Forest and Wood Management & 19.2 & 5.8 & 231 & 108 & 339 \\
\hline Ecotrophology & 84.7 & 2 & 132 & 372 & 504 \\
\hline Medical Sciences & 51.4 & 10.2 & 1861 & 2157 & 4018 \\
\hline Human Medicine & 49.6 & 5.3 & 1395 & 1519 & 2914 \\
\hline Dentistry & 42.6 & 9 & 332 & 249 & 581 \\
\hline Veterinary Medicine & 72.7 & 8.7 & 90 & 205 & 295 \\
\hline Pharmaceutics & 69.6 & 2.6 & 44 & 184 & 228 \\
\hline Engineering & 14.6 & 12.3 & 12,727 & 27,90 & 15,517 \\
\hline Machine Engineering & 10.9 & 2.5 & 5299 & 935 & 6234 \\
\hline Mining and Metallurgy & 11.2 & 4.8 & 728 & 103 & 831 \\
\hline Architecture & 44.9 & 3.9 & 944 & 911 & 1855 \\
\hline Civil Engineering & 17.8 & 3.3 & 1514 & 443 & 1957 \\
\hline Traffic Engineering & 3.4 & .3 & 135 & 5 & 140 \\
\hline Electrical Engineering & 4 & 1.3 & 3179 & 209 & 3388 \\
\hline Engineering Economics & 14.9 & 3.3 & 928 & 184 & 1112 \\
\hline Arts & 58.7 & 7.1 & 646 & 1109 & 1755 \\
\hline Fine Arts & 71.4 & 2.2 & 94 & 247 & 341 \\
\hline Dramatic Arts & 59 & 1.8 & 101 & 107 & 208 \\
\hline Musicology & 52.5 & 2.3 & 280 & 376 & 656 \\
\hline Design & 58.2 & 2 & 171 & 379 & 550 \\
\hline Total & 40.5 & 22.1 & 34,302 & 28,165 & 62,467 \\
\hline
\end{tabular}

This table shows the full list of fields of study employed and the numbers of observation of individuals in the microdata holding a degree in the respective field as well as the average percentage of female students prevailing in the respective year of graduation. Source: Statistical Yearbooks \& Microcensus 2003-2011, own calculations

\section{References}

Abramitzky, R., Delavande, A., \& Vasconcelos, L. (2011). Marrying up: the role of sex ratio in assortative matching. American Economic Journal: Applied Economics, 3, 124-157.

Anelli, M. \& Peri, G. (2017). The effects of high school peers' gender on college major, college performance and income. The Economic Journal. https://onlinelibrary.wiley.com/doi/abs/10.1111/ecoj. 12556. https://onlinelibrary.wiley.com/doi/pdf/10.1111/ecoj.12556.

Angrist, J. D. (2002). How do sex ratios affect marriage and labor markets? Evidence from America's second generation. Quarterly Journal of Economics, 117, 997-1038.

Bertrand, M., Pan, J. \& Kamenica, E. Gender identity and relative income within households. Quarterly Journal of Economics. https://doi.org/10.1093/qje/qjv001, 571-614 (2015). 
Bičáková, A. \& Jurajda, S. Field-of-study homogamy. IZA Discussion Paper No. 9844 (2016).

Bitler, M. P., \& Schmidt, L. (2012). Birth rates and the Vietnam draft. American Economic Review: Papers \& Proceedings, 102, 566-569.

Blossfeld, H.-P. \& Timm, A. Educational systems as marriage markets in modern societies: a conceptual framework. In Blossfeld, H.-P. \& Timm, A. (eds) Who marries whom? Educational systems as marriage markets in modern societies, 1-18 (European Studies of Population Vol. 12, 2003).

Bredemeier, C., \& Juessen, F. (2013). Assortative mating and female labor supply. Journal of Labor Economics, 31, 603-631.

Chiappori, P.-A., Fortin, B., \& Lacroix, G. (2002). Marriage market, divorce legislation, and household labor supply. Journal of Political Economy, 110, 37-72.

Destatis. Statistical Yearbooks for the Federal Republic of Germany 1952-1992. Wiesbaden (1952-1992).

Edlund, L. (1999). Son preference, sex ratios, and marriage patterns. Journal of Political Economy, 107, $1275-1304$.

Ermisch, J., Francesconi, M., \& Siedler, T. (2006). Intergenerational mobility and marital sorting. Economic Journal, 116, 659-679.

Fiorio, C. V. \& Verzillo, S. Looking in your partner's pocket before saying "Yes!" Income assortative mating and inequality. DEMM Working Paper 2/2018 (2018).

Fisman, R., Iyengar, S. S., Kamenica, E., \& Simonson, I. (2006). Gender differences in mate selection: evidence from a speed dating experiment. Quarterly Journal of Economics, 121, 673-697.

Goldin, C., Katz, L. F., \& Kuziemko, I. (2006). The Homecoming of American College Women: the reversal of the college gender gap. Journal of Economic Perspectives, 20, 133-156.

Greenwood, J., Guner, N., Kocharkov, G. \& Santos, C. (2014). Marry your like: assortative mating and income inequality. American Economic Review: Papers \& Proceedings 104, 348-353, Corrigendum: http://www.jeremygreenwood.net/papers/ggksPandPcorrigendum.pdf.

Grossbard, S., \& Granger, C. (1998). Women's jobs and marriage: baby-boom versus baby-bust (Travail des Femmes et Mariage: du baby-boom au baby-bust). Population (French version), 53, 731-752.

Grossbard-Shechtman, S. \& Neideffer, M. Women's hours of work and marriage market imbalances. In Persson, I. \& Jonung, C. (eds.) Economics of the family and family policies (London: Routledge, 1997).

Hyslop, D. R. (2001). Rising U.S. earnings inequality and family labor supply: the covariance structure of intrafamily earnings. American Economic Review, 91, 755-777.

Lavy, V., \& Schlosser, A. (2011). Mechanisms and impacts of gender peer effects at school. American Economic Journal: Applied Economics, 3, 1-33.

Mansour, H., \& McKinnish, T. (2018). Same-occupation spouses: preferences and search costs. Journal of Population Economics, 31, 1005-1033.

McKinnish, T. G. (2007). Sexually integrated workplaces and divorce: another form of on-the-job search. Journal of Human Resources, 42, 331-352.

Microcensus. Research Data Centres of the Federal Statistical Office and the Statistical Offices of the Länder (2003-2011).

Negrusa, B., \& Oreffice, S. (2010). Quality of available mates, education, and household labor supply. Economic Inquiry, 48, 558-674.

Pestel, N. (2017). Marital sorting, inequality and the role of female labour supply: evidence from East and West Germany. Economica, 84, 104-127.

Skopek, J., Schulz, F., \& Blossfeld, H.-P. (2011). Who contacts whom? Educational homophily in online mate selection. European Sociological Review, 27, 180-195.

Destatis. Studierende an Hochschulen - Fachserie 11/4.1, 1993-2012. Wiesbaden (1993-2012).

Zölitz, U. \& Feld, J. (2021) The effect of peer gender on major choice in business school. Management Science forthcoming. 